\title{
USO DE HEMOGLOBINA (Hb) PARA DEFINIR ANEMIA POR DEFICIENCIA DE HIERRO (IDA)
}

\author{
Gustavo F. Gonzales¹, Paola Olavegoya, Cinthya Vásquez-Velásquez¹, Dulce Esperanza Alarcón-Yaquetto.
}

\begin{abstract}
RESUMEN
La anemia es un problema de salud pública mundial que afecta tanto la salud como la supervivencia de las personas. Se estima que $25 \%$ de la población mundial la padece. A pesar de que las mayorías de países del mundo realizan intervenciones desde hace cincuenta años para reducir las tasas de anemia, estas han resultado poco satisfactorias. Entre los argumentos que se plantean a este bajo éxito se considera a una baja adherencia al consumo de suplementos de hierro. El descubrimiento de la hepcidina en el año 2000 ha cambiado nuestro conocimiento sobre los mecanismos que regulan la homeostasis de hierro, con lo cual se demuestra que los procesos inflamatorios que en $42 \%$ se asocia a anemia en el mundo no va a responder a la intervención con hierro oral, debido al incremento en el valor de hepcidina por la inflamación. En esta revisión igualmente se discute que los criterios empleados para determinar los puntos de corte en niños y gestantes para definir anemia por deficiencia de hierro no concuerdan con las cifras de normalidad establecidas en varios países en el mundo. Así, el punto de corte de $11 \mathrm{~g} / \mathrm{dL}$ de $\mathrm{Hb}$ definido para determinar anemia en gestantes y niños está por encima de la media-dos desviaciones standard de las poblaciones evaluadas. Igualmente se describen evidencias que permiten sugerir que la corrección de la hemoglobina por la altura sería innecesaria y estaría aumentando erróneamente las prevalencia de anemia en poblaciones de altura. En conclusión, las evidencias sugieren que el ajuste de hemoglobina por la altura es innecesario y aumenta de manera significativa la prevalencia de anemia en la altura. Se debe redefinir el punto de corte de $\mathrm{Hb} 11 \mathrm{~g} / \mathrm{dL}$ para diagnosticar anemia en niños menores de 60 meses y en gestantes. Se deben de considerar evaluar el contenido de hierro corporal y otros biomarcadores del hierro, siempre ajustándolos por el aporte inflamatorio, de esta manera podemos distinguir exactamente la prevalencia de anemia por deficiencia de hierro, excluyendo los demás tipos.
\end{abstract}

Palabras claves: Anemia; Deficiencia de hierro; Inflamación; Gestantes; Neonatos (Fuente DeCS BIREME).

\section{USE OF HEMOGLOBIN (HB) FOR IRON DEFICIENCY ANEMIA (IDA) DIAGNOSIS}

\begin{abstract}
Anemia is a worldwide public health problem that affects both the health and survival of people. It is estimated that $25 \%$ of the world population suffers it. Although most of the countries have been intervening during fifty years to reduce the rates of anemia, these efforts are unsatisfactory. Among the arguments used to explain this low success, is the low adherence to the consumption of iron supplements. The hepcidin discovery in 2000 has changed our knowledge about the mechanisms that regulate iron homeostasis, which shows that the inflammatory processes, which are responsible for $42 \%$ of anemia cases in the world will not respond to the intervention with oral iron, due to the increase in the value of hepcidin by inflammation. In this review it is also argued that the criteria used to determine the cut-off points in children and pregnant women to define iron deficiency anemia do not agree with the normality figures established in several countries in the world. Thus, the cut-off point of $11 \mathrm{~g} / \mathrm{dL}$ of $\mathrm{Hb}$ defined to determine anemia in pregnant women and children is above the mean-two standard deviations of the populations evaluated. Evidence is also described that suggests that the correction of hemoglobin by altitude of residence would be unnecessary and erroneously increasing the prevalence of anemia in high-altitude populations. To sum up, the evidence suggests that adjusting hemoglobin for altitude is unnecessary, and significantly increases the prevalence of anemia in high altitude population. The $\mathrm{Hb}$ cut-off point $11 \mathrm{~g} / \mathrm{dL}$ should be redefined to diagnose anemia in children under 60 months of age and in pregnant women. In a way to better define iron deficiency anemia, other biomarkers should be considered to evaluate the content of body iron, always adjusting for the inflammatory contribution. By these means we can accurately distinguish the prevalence of iron deficiency anemia, excluding the other types.
\end{abstract}

Key words: Anemia; Iron deficiency; Inflammation; Pregnant women; Neonates (Source: MeSH NLM).

\section{INTRODUCCIÓN}

El hierro es un mineral importante para la vida, sin embargo, su exceso puede ser dañino para la salud. El conocimiento del complejo mecanismo de la homeostasis de hierro se ha visto acelerado debido a la identificación de una serie de proteínas claves en su regulación y que han ocurrido en un breve periodo de 5 años entre 1996 y 2001 y que incluyen una proteína importadora de hierro (DMT1, Transportador de Metales divalentes 1), una proteína exportadora de hierro (ferroportina), y el principal regulador de la homeostasis de hierro, la hepcidina (Anderson y Frazer, 2017). Por ello el contenido de hierro en el cuerpo tiene un mecanismo fino de regulación

Instituto de Investigaciones de la Altura y Facultad de Ciencias y Filosofía (Laboratorios de Investigación y Desarrollo; y Departamento de Ciencias Biológicas y Fisiológicas). Universidad Peruana Cayetano Heredia

Citar como: Gonzales GF, Olavegoya P, Vásquez-Velásquez C, Alarcón-Yaquetto DE. Uso de hemoglobina (Hb) para definir anemia por deficiencia de hierro. Rev Peru Investig Matern Perinat 2018; 7(1):37-54. DOI. https://doi.org/10.33421/inmp.2018108

Recibido: 10-06-18 Aprobado: 30-06-18 


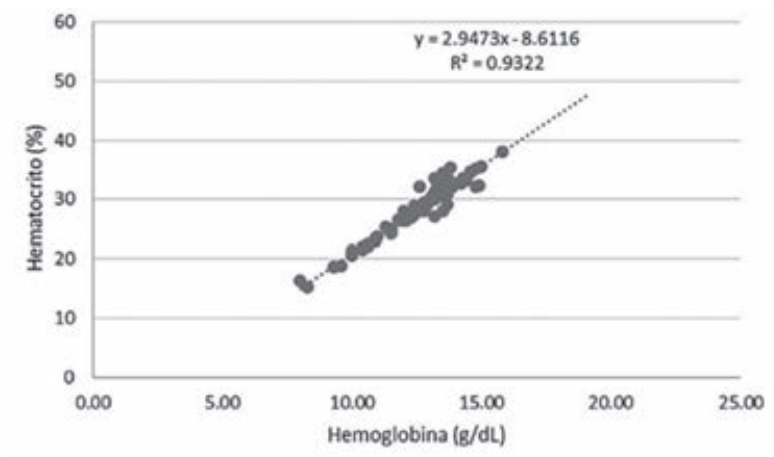

Figura 1. Correlación entre los niveles de hemoglobina $(\mathrm{g} / \mathrm{dL})$ y del hematocrito (\%) en infantes de 6 a 24 meses nativos de Puno $(3800 \mathrm{~m})$. Coeficiente de Pearson $=0.97 ; p<0.001$

basado en la hormona hepcidina producida por el hígado. El $70 \%$ del hierro del organismo humano se encuentra en la hemoglobina. Por ello la OMS recomienda la medición de hemoglobina como una forma de diagnosticar anemia por deficiencia de hierro, definiendo a su vez puntos de cortes de la hemoglobina para el diagnóstico de anemia (OMS, 2011). Así en gestantes y en niños de 6 a 59 meses de edad, la anemia se define como valores de hemoglobina $<11 \mathrm{~g} / \mathrm{dL}$. Este criterio es bastante lógico y se aúna al hecho que la medición de la hemoglobina es fácil y de bajo costo. Más aún en lugares donde no es posible medir la hemoglobina se puede usar el hematocrito que resulta de la relación entre los cuerpos formes y el volumen plasmático. Dado que el mayor porcentaje de la masa forme corresponde a los glóbulos rojos se considera el hematoc ito un valor relac onado al o nteo de glóbulos rojos y a la concentración de hemoglobina (Figura 1). Lo que no queda claro es como se ha establecido el punto de corte de $11 \mathrm{~g} / \mathrm{dL}$ de hemoglobina.

Adicional a lo anterior, la hemoglobina lamentablemente no es un marcador directo del estatus del hierro, debido a que sus niveles normales varían por la edad, el sexo, la altitud geográfica, por el embarazo. Igualmente sus valores también se afectan por el hábito de fumar (Milman y Pedersen, 2009) o por cocinar con combustible de biomasa (leña, champa, bosta) (Accinelli y Leon-Abarca, 2017). Igualmente, la concentración de hemoglobina se puede afectar por procesos inflamatorios (anemia inflamatoria), por deficiencia de vitamina B12 (anemia perniciosa) (Smith y col, 2018), o por otras vitaminas y micronutrientes (Vitamina A, folatos, riboflavina, cobre), o por alteraciones genéticas (ej. Talasemia) (Figura 2).

Aunque la OMS reconoce que la $\mathrm{Hb}$ no es un marcador directo del estatus de hierro lo sigue recomendando para evaluar la IDA (OMS, 2011). La simple medición de Hb es en la mayoría de países del mundo el único marcador para definir anemia por deficiencia de hierro y sirve para generar intervenciones de suplementación de hierro. El deso noć miento que la mitad de los a sos de anemia se deben a factores diferentes a la deficiencia de hierro puede explicar la baja respuesta a las intervenciones.

- Deficiencia de vitaminas

- Alteraciones genéticas

- Infecciones agudas (ej. Malaria)

- Infecciones crónicas (ej. TB, VIH)

- Condiciones inflamatorias (ej. artritis reumatoides)

- Cáncer



Figura 2. Tipos de anemia. La anemia por deficiencia de hierro (IDA) se observa en el $50 \%$ de casos de anemia en el mundo. La anemia inflamatoria infecciosa y no infecciosa se observa en el $42 \%$ de casos. Otras anemias $8 \%$ de casos, entre ellas alteraciones genéticas y deficiencia de vitaminas. 


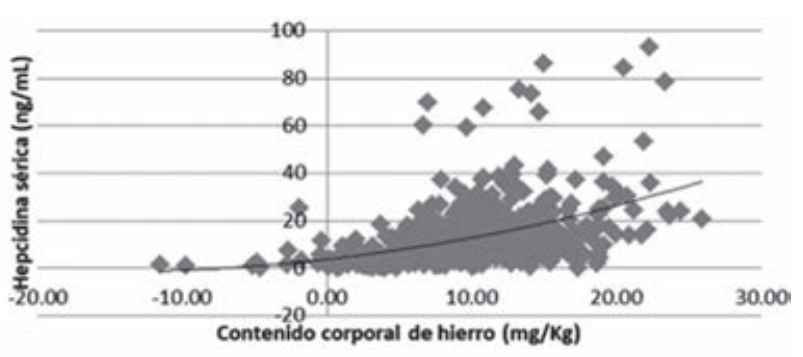

Figura 3. Asociación entre el Contenido Corporal de Hierro (mg/ $\mathrm{Kg}$ ) y el nivel de hepcidina sérica $(\mathrm{ng} / \mathrm{mL})$ en adultos peruanos, varones y mujeres residentes a baja y gran altitud. $Y=0.02$ $X^{2}+0.68 X+3.74$. Coeficiente de Pearson $=0.45 ; p<0.01$

El o noc miento sobre la homeostasis de hierro se ha modificado bastante a partir del descubrimiento en el 2000 de la hepcidina, una hormona producida en el hígado. Esta hormona se pensó inicialmente que era un péptido con propiedades antibacterianas. Pronto se determinó que la actividad antibacteriana se debía a su efecto sobre la disponibilidad de hierro. Los microorganismos requieren para su supervivencia del hierro, y hacen uso del hierro del huésped para reproducirse. El huésped se protege produciendo hepcidina a través del hígado que va a at uar tanto a nivel duodenal inhibiendo la absoric ón de hierro como a nivel de las células de almacenaje, impidiendo su salida (Nairz y col, 2018). Esta propiedad de que un proceso infeccioso aumente los niveles de hepcidina determina un cuadro de anemia denominado "anemia inflamatoria". En este caso la intervención con suplemento de hierro oral será inefectiva.

Cuando el organismo tiene may res requerimientos de hierro como en la etapa de crecimiento y desarrollo, o durante el embarazo o cuando hay pérdidas sanguíneas, el organismo inhibe la producción de hepcidina y facilita con ello el transporte a través de la ferroportina del hierro que entra a las é lulas entéria $s$ en el duodeno o los libera de las zonas de almacenaje. Así a menor contenido corporal de hierro, los niveles de hepcidina sérica disminuyen mientras a mayor contenido corporal de hierro, los niveles de hepcidina aumentan (Figura 3) para evitar la sobrecarga de hierro, que puede ser perjudicial para la salud.

Las nee sidades diarias de hierro a través de la dieta son bajas debido a que el hierro contenido en el organismo no se excreta sino más bien se recicla. Así una persona adulta normal requerirá absorber vía duodenal $1 \mathrm{mg} /$ día de hierro para tener suficiencia de hierro. En caso del embarazo, la gestante va a requerir en el segundo y tercer trimestre transportar hierro a la placenta y feto. Para ello se requiere de una maø $r$ absorc ón de hierro a nivel de duodeno. Antes de la era de la hepcidina, se consideraba la necesidad de triplicar la ingesta de hierro de $9 \mathrm{mg} /$ día a $27 \mathrm{mg} / \mathrm{día}$. En la actualidad este concepto se ha modificado pues la disponibilidad de hierro va a depender más del nivel de hepcidina que de la cantidad de hierro en la dieta (Figura 4).

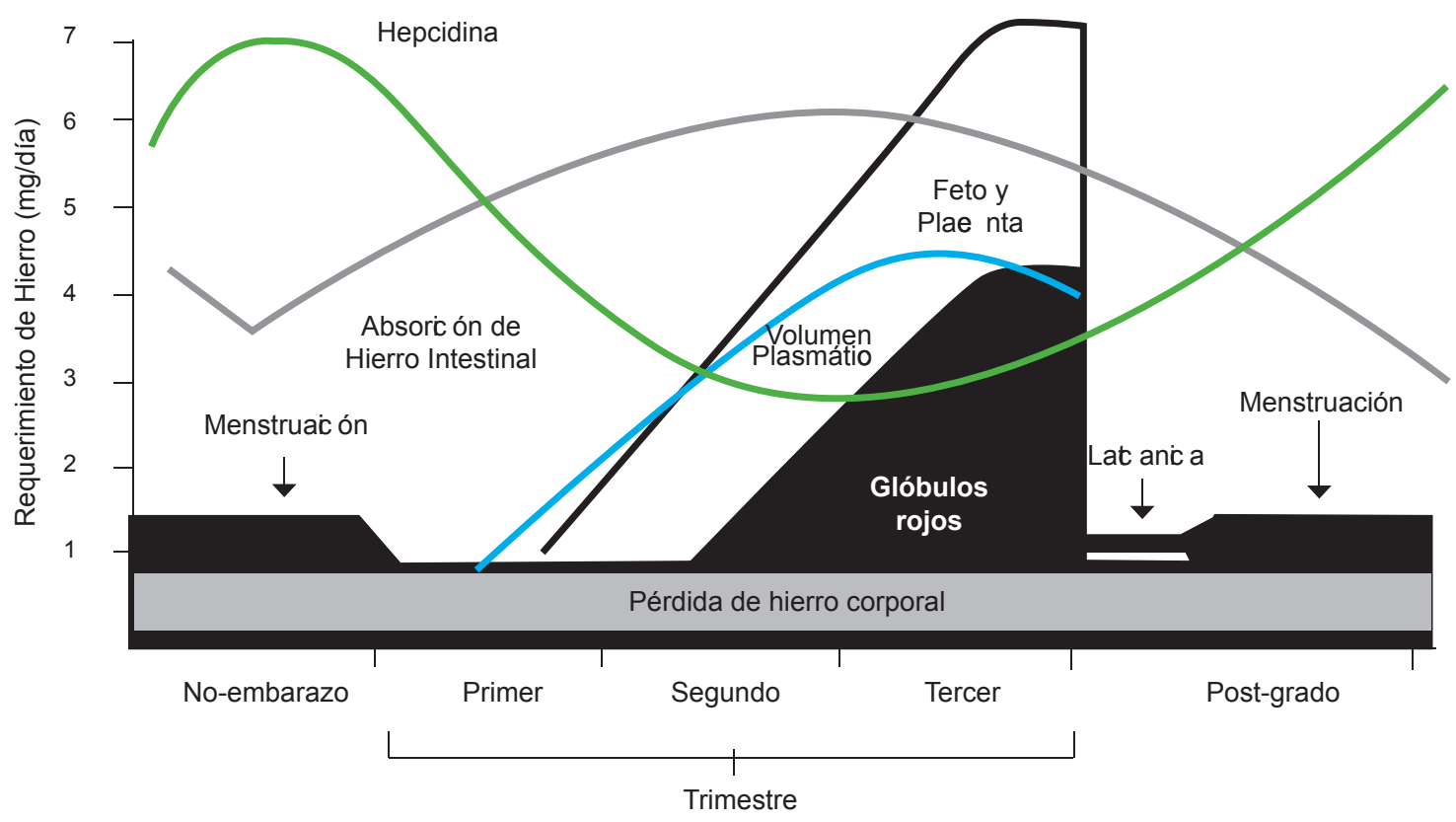

Figura 4. Homeostasis del hierro durante la gestación. A partir del segundo trimestre los niveles de hepcidina sérica disminuyen y aumenta la absorción de hierro intestinal a nivel del duodeno. El volumen plasmático aumenta más que la masa hemática generando con ello una hemodilución asociada a mayor eritropoyesis. 


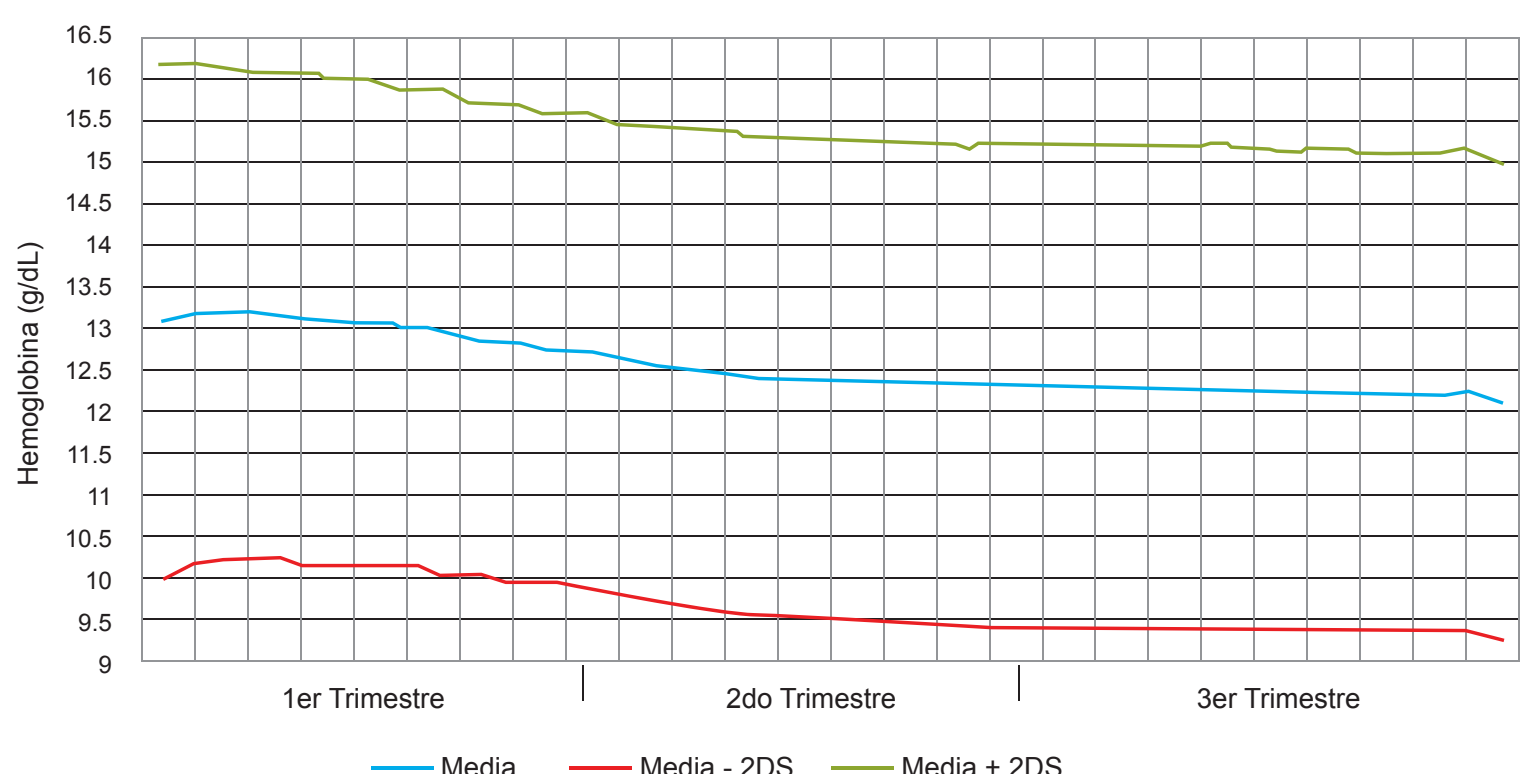

Figura 5. Niveles de hemoglobina (g/dL) por semana de gestación: Superior: media+2 DS; Intermedio: media; Inferior: media-2 DS. Fuente: propia basado en base de datos de CENAN en gestantes del Perú.

Se estima que los infantes nacidos a pre-término están en mayor riesgo de deficiencia de hierro. Para reducir este riesgo los niveles de hepcidina disminuyen en estos infantes en los primeros 4 meses de vida con la finalidad de favorecer la absorción de hierro (Uijterschout y col, 2016).

De aa erdo a lo anterior queda $\mathrm{k}$ aro que durante el embarazo hay un proceso de eritropoyesis aumentando la producción de glóbulos rojos con la finalidad de acumular una mayor cantidad de hierro necesario para la placenta y feto (Figura 4). Esto sin embargo no se traduce en un aumento en la cone ntrać ón de hemoglobina. Por el contrario como puede verse en la Figura 5, los niveles de hemoglobina caen conforme avanza la gestación. Esto se debe a un proceso denominado hemodilución que será tratado más adelante.

Si la reducción de la $\mathrm{Hb}$ durante la gestación es debido a un proceso de hemodilución más que un indicador de una deficiencia de hierro, surge la pregunta de porque se suplementa con hierro a toda gestante sea o no anémica.

En esta revisión trataremos de demostrar que algunos conceptos aún vigentes y que determinan el uso masivo de suplemento de hierro en las gestantes y en niños menores de 5 años no se basan en las evidencias científicas. Igualmente se evaluará la utilidad del uso de hemoglobina como único criterio para la suplementación de hierro.

Se han planteado criterios en contra del uso único de la hemoglobina o mo mara dor del estatus de hierro de una población. Estos criterios se detallan en la Tabla 1.
Tabla 1. Criterios que están en o ntra del uso de la hemoglobina como marcador único del estatus de hierro de una población

Criterios en contra para el uso de sólo la $\mathrm{Hb}$ para determinar estatus de hierro en una población

1. No se ha tomado en cuenta que la concentración de hemoglobina puede variar por hemodilución (embarazo normal) o por hemoconcentración (embarazo preeclámptico o vida en la altura) sin que ello signifique que ha disminuido o aumentado el contenido de hierro corporal. Esto lo hace un marcador poco fiable.

2. La anemia por inflamación (ej. Parasitosis, frecuente en la selva) se asocia a niveles bajos de $\mathrm{Hb}$ pero no responde al tratamiento oral o $\mathrm{n}$ hierro.

3. La ontogenia de la hemoglobina fetal a hemoglobina adulta.

4. Incongruencias entre las estadísticas de desnutrición crónica y anemia infantil

5. Resultados clínicos favorables en neonatos y gestantes o $n$ valores de anemia leve en la madre.

Más aún el hallazgo de estudios que demuestran que el suplemento de hierro puede aumentar la proporción de sujetos con eritrocitosis o niveles elevados de glóbulos rojos pone en tela de juicio si esto puede generar iatrogenia. El estudio de la asociación de la hemoglobina materna con el resultado del embarazo ha permitido demostrar que hay una asociación en forma de "U" donde valores bajos de hemoglobina (nivel de anemia moderada y severa) y valores altos de hemoglobina (eritrocitosis o $\mathrm{Hb}>14,5 \mathrm{~g} / \mathrm{dL}$ ) están asociados a 
Tabla 2. Prevalencia de anemia y número de personas afectadas en el mundo

\begin{tabular}{lrrrr}
\hline \multicolumn{1}{c}{ GRUPO } & $\begin{array}{c}\text { Prevalenc a de anemia } \\
(\%)\end{array}$ & IC al 95\% & $\begin{array}{c}\text { Personas afectadas } \\
\text { (millones) }\end{array}$ & IC al 95\% \\
\hline$<5$ años & 47.4 & $45.7-49.1$ & 293 & $283-303$ \\
\hline Niños en edad escolar & 25.4 & $19.9-30.9$ & 305 & $238-371$ \\
Embaraz das & 41.8 & $39.9-43.8$ & 56 & $54-59$ \\
No embarazadas & 30.2 & $28.7-31.6$ & 468 & $446-491$ \\
Varones & 12.7 & $8.6-16.9$ & 260 & $175-345$ \\
Adulto ma甲 $r$ & 23.9 & $18.3-29.4$ & 164 & $126-202$ \\
TOTAL & 24.8 & $22.9-26.7$ & 1620 & $1500-1740$ \\
\hline
\end{tabular}

Fuente: McLean y col (2009) basado en datos del sistema de información nutricional de OMS para los años 1993-2005.

riesgos en la gestante y en el neonato (Dewey y Oaks, 2017). Esto es importante conocer para determinar las necesidades de intervención con suplemento de hierro. En varios estudios de intervención se ha podido demostrar que la tasa de eritrocitosis aumenta con la intervención y ello puede generar un riesgo para la salud de la madre y del producto de la gestación (PeñaRosas y col, 2015).

\section{EPIDEMIOLOGÍA DE LA ANEMIA}

Entre las primeras estadísticas globales de anemia se encuentran la de 1985, donde reportan que 30\% de la población es anémica. Entre grupos, $43 \%$ de niños menores de 5 años son anémicos, $35 \%$ de no embarazadas y $51 \%$ de embarazadas (De Maeyer y Adelier-Tegman, 1985).

Una segunda estadística se publica en 1992 por la OMS específica para mujeres usando datos de 1988 , donde $51 \%$ de las embarazadas son anémicas y $35 \%$ de no embarazadas son anémicas (WHO, 1992).

Estas estadísticas son difíciles de comparar porque usan metodologías diferentes y no incluyen la población China que representa un importante segmento de la población mundial.

Basados en datos de la OMS entre 1993 y 2005 (McLean y col, 2009), se reportan que unos mil seiscientos millones de personas en el mundo sufren de anemia (Tabla 2) y se estima que la mitad es por deficiencia de hierro (Figura 2). Esto afecta principalmente a niños menores de 5 años, y a mujeres en edad reproductiva.

Desde hace cincuenta años, la mayoría de gobiernos en el mundo realiza intervenciones para suplementar o fortificar alimentos con hierro y mejorar programas de nutrición en los países. Si bien es cierto la prevalencia de desnutrición crónica en niños menores de 5 años se ha reducido significativamente, no ocurre lo mismo con la anemia cuyas prevalencias se mantienen altas.
La prevalencia global de anemia para el periodo 19932005 es de $24.8 \%$, en niños menores de 5 años es de $47.4 \%$, en mujeres embarazadas de $41.8 \%$ y $30.2 \%$ en no embarazadas (Mc Lean y col, 2009). Las más altas prevalencias de anemia se observen en el África Subsahariana y en el Sudeste Asiático. En esta estadística, no hay información sobre la contribución relativa de los factores causales, y con ello se dificulta como tratar el problema, dado que la respuesta a los diferentes tipos de anemia es diferente.

Otro análisis basado en estudio sistemático de muestras poblacionales representativas se presenta para el periodo 1995 y 2011 que incluyen la prevalencia de anemia global y anemia severa en niños (6-59 meses) y en mujeres embarazadas y no embarazadas de 107 países en el mundo (Stevens y col, 2013). Los niveles promedio de hemoglobina han mejorado ligeramente entre 1995 y 2011 (Tabla 3).

Tabla 3. Cone ntrac ón de hemoglobina a nivel mundial según grupo de riesgo a anemia en los años 1995 y 2011

\begin{tabular}{lcccc}
\hline & $\begin{array}{c}\text { Hemoglobina } \\
\mathbf{( g / d L )} \\
\mathbf{1 9 9 5}\end{array}$ & IC al 95\% & $\begin{array}{c}\text { Hemoglobina } \\
\mathbf{( \mathbf { g } / \mathbf { d L } )}\end{array}$ & IC al 95\% \\
& 12.5 & $12.3-12.6$ & 12.6 & $12.4-12.8$ \\
\hline No & & $\mathbf{2 0 1 1}$ & \\
\hline embarazadas & 11.2 & $11.1-11.3$ & 11.4 & $11.2-11.6$ \\
$\begin{array}{l}\text { Embaños } \\
<60 \text { meses }\end{array}$ & 10.9 & $10.7-11.1$ & 11.1 & $11.0-11.6$ \\
\hline
\end{tabular}

Fuente: Stevens y col, 2013

Tabla 4. Prevalencia de anemia a nivel mundial según grupo de riesgo a anemia en los años 1995 y 2011

\begin{tabular}{lllll}
\hline & $\begin{array}{c}\text { Prevaleni a } \\
\text { de anemia } \\
1995\end{array}$ & IC al 95\% & $\begin{array}{c}\text { Prevalencia } \\
\text { de anemia } \\
2011\end{array}$ & ICal95\% \\
\hline $\begin{array}{l}\text { No } \\
\text { embaraz das }\end{array}$ & 33 & $29-37$ & 29 & $24-35$ \\
\hline $\begin{array}{l}\text { Embaraz das } \\
\text { Niños }\end{array}$ & 43 & $38-47$ & 38 & $34-43$ \\
$<60$ meses & 47 & $43-51$ & 43 & $38-47$ \\
\hline
\end{tabular}

Fuente: Stevens y col, 2013 


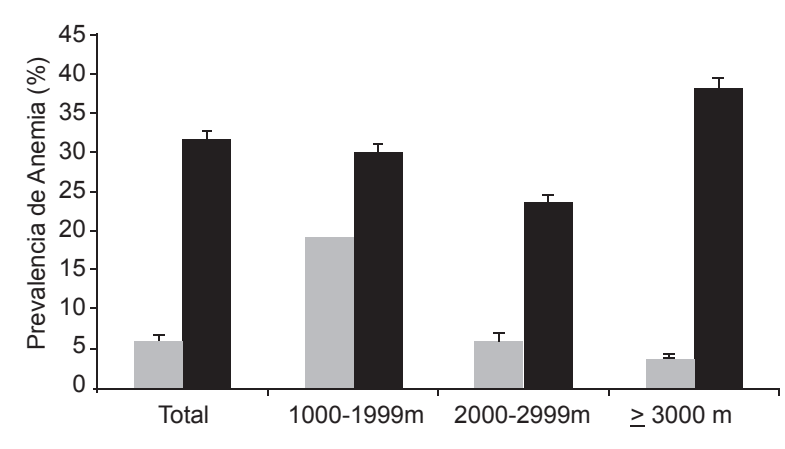

Figura 6. Prevalencia de anemia en gestantes peruanas antes (columna en red) o después (columna en negro) de corregir la hemoglobina por altura.

Para 2011, las menores concentraciones de hemoglobina y las más altas prevalencias de anemia se observan en el sur de Asia y en África central y occidental (Stevens y col, 2013).

De acuerdo a la publicación de Stevens y col (2013), para 2011 (Tabla 4), los niños menores de 5 años en un 43\% (38-47\%) presentan anemia. La OMS ha establecido que cuando $\geq 40 \%$ de una población presenta una enfermedad se considera como un problema grave de salud pública. Si del 20 al 39.9\% presenta la enfermedad se considera como problema moderado de salud pública, de 5 a 19.9\% como problema leve y cuando $<5 \%$ de la población estudiada tiene la enfermedad se considera que no hay problema de salud pública (de Benzoit y col, 2008).

En estas dos últimas estadísticas el cálculo de prevalencia de anemia en poblaciones por encima de 1000 metros se hace luego de ajustar la hemoglobina por altura.

En un estudio usando la base del Sistema Informático Perinatal regulado por el Ministerio de Salud, para hospitales públicos del Perú, la frecuencia de anemia en una muestra de 379,816 gestantes, es de $18.1 \%$ (IC 99 $\%$ : 17.9-18.2 \%). La prevalencia de anemia leve es de $16.6 \%$ (IC $99 \%: 16.4-16.7 \%$ ), la de anemia moderada es de $1.4 \%$ (IC $99 \%$ : 1.3-1.4\%) y la de anemia severa de 0.1 \% (IC 99 \%: 0.1-0.2 \%). En relación a la región geográfica, las prevalencias de anemia son más altas en la selva baja $(28.8 \%)$ y en la costa $(27.9 \%)$ que en la selva alta (16.2\%) y en la sierra (5.9\%). Estos resultados han sido elaborados sin utilizar la corrección de la hemoglobina por altura (Gonzales y col, 2011). La prevalencia de anemia puede incrementarse hasta 5 veces luego de la corrección de la hemoglobina por altura. El incremento es mucho mayor por encima de los $3000 \mathrm{~m}$ de altura (Figura 6). Esto modifica el problema de salud pública de grados leve a moderado a magnitud de grave luego de la o rreć ón de la hemoglobina por la altura.

En el Perú se han descrito prevalencias tan altas de alrededor de $70 \%$ en los niños menores de 5 años de Puno $(3800 \mathrm{~m})$, y valores a nivel nacional de $43.6 \%$ en menores de 3 años, a pesar de intensos programas de intervención (INEI, 2017). En estas estadísticas oficiales se utiliza la corrección de hemoglobina por la altura.

\section{Punto de corte para definir anemia: Criterio OMS}

La OMS define en 1968 el criterio para definir anemia en niños menores de 5 años y en gestantes como valores de $\mathrm{Hb}$ menores de $11 \mathrm{~g} / \mathrm{dl}$. En varones adultos como $\mathrm{Hb}$ menor de $13 \mathrm{~g} / \mathrm{dL}$ y en mujeres adultas no gestantes premenopáusicas como $\mathrm{Hb}<12 \mathrm{~g} / \mathrm{dL}$. Esta definición ha sido criticada por muchos autores (Domellöf y col, 2002; Little, 2005; Beutler y Waalen, 2006; Gonzales y col, 2018) y en muchos países no se utilizan los puntos de corte definidos por OMS (Muñoz y col, 2018).

En 1989 se definen las categorías de anemia como leve, moderada y severa. Numerosas publicaciones sobre anemia en gestantes y en niños menores de 5 años muestran que la anemia leve no solo no es dañina, sino que en ese rango de $\mathrm{Hb}$ se observan las mejores respuestas de salud para la madre, el recién nacido y los niños. La OMS presenta sus estadísticas mostrando el valor de anemia total y la prevalencia de anemia severa (Stevens, 2013). Esto puede sugerir que no considera a la anemia leve como problema, aunque no lo destaca tal a al.

La OMS define en 1989 corregir el punto de corte de la $\mathrm{Hb}$ por cada nivel de altitud a partir de los 1000 metros de altura. Esta corrección eleva las prevalencias de anemia particularmente en poblaciones por encima de 3,000 metros de altura (Gonzales y col, 2018).

Esta corrección es universal y se ejecuta en todos los países con poblaciones que viven por encima de los $1000 \mathrm{~m}$. La corrección se basa en el concepto que la Hb aumenta conforme aumenta la altitud de residencia. Los estudios de investigación han demostrado, sin embargo, que el aumento de la $\mathrm{Hb}$ por la altitud de residencia no es universal. En efecto poblaciones con mayor antigüedad generacional tienen menor valor de $\mathrm{Hb}$ que poblaciones o $n$ menor antigüedad generac onal viviendo a la misma altitud.

Existen voces discrepantes sobre si la sola medición de la $\mathrm{Hb}$ y el uso de los puntos de corte de $\mathrm{Hb}$ para definir anemia recomendados por la OMS y aplicados por la mayoría de países del mundo son adecuados. Aún no está $\mathrm{t}$ aro si es la anemia per se o la deficiencia de hierro o ambas que afectan la salud de la madre y del neonato.

\section{Aspectos no tomados en cuenta desde la definición de anemia}

La definición de anemia en niños menores de 5 años y en embarazadas se da a través de la Organización 
Mundial de la Salud (OMS) en el año 1968 cuando aún no se conocían muchos de los reguladores de la homeostasis de hierro y de la eritropoyesis en particular de la hepcidina y de la eritroferrona que se identifican a partir del año 2000.

La hepcidina es producida en el hígado y se une a la ferroportina internalizándolo al interior de la célula y produciendo su degradación inhibiendo con ello la absorc ón de hierro en el duodeno o su liberać ón de los sitios de almacén en el organismo. La eritroferrona es producida por acción de la eritropoyetina en el eritroblasto y su ac ón al ser liberado a la ć ra lać ón es inhibir la secreción de hepcidina, favoreciendo con ello la entrada de hierro a la circulación y su disponibilidad en el eritroblasto para favorecer la eritropoyesis (Vallet y col, 2018).

El hierro siendo un mineral importante para la supervivencia celular, en exceso puede producir entre otros stress oxidativo y ser prejudicial disminuyendo la supervivencia celular. Por ello, el hierro no se excreta del organismo y más bien se reć $\mathrm{b} a$; se estima que a da día hay una pérdida de $1 \mathrm{mg}$ por descamación de células entéricas o por pérdidas por sudor. Así, cada día debe absorberse de la dieta $1 \mathrm{mg}$ para reponer la pérdida. Si en la dieta se o nsume $10 \mathrm{mg}$ de hierro se ha cala lado que se absorbe un $10 \%$ para cubrir la demanda de $1 \mathrm{mg} / \mathrm{día}$.

El hierro al ingresar a la ćra lac ón lo hae unido a la transferrina una proteína que se une en la membrana celular al receptor de transferrina para depositar hierro en las células. Dentro de las células en particular en el hígado y en los macrófagos se une a la ferritina. En la sangre se le encuentra unida a la hemoglobina, fenómeno que ocurre durante la eritropoyesis en la médula ósea y en el músculo se une a la mioglobina.

Existe una forma circulante de ferritina que correlaciona con la ferritina en las zonas de almacén por lo cual se usa la medición de ferritina sérica como un marcador de la reserva de hierro en el cuerpo. En relación a la transferrina existe un receptor soluble de transferrina (RsTf) que se inc ementa a medida que aumenta la nee sidad de hierro. Para el caso de la ferritina se utiliza como punto de corte para definir deficiencia de hierro en gestantes valores de $12 \mathrm{ng} / \mathrm{mL}$ y otros utilizan como punto de corte $15 \mathrm{ng} / \mathrm{mL}$ (Daru y col, 2017). Para niños menores de 5 años se uisa como punto de corte $12 \mathrm{ng} / \mathrm{mL}$.

Numerosos estudios han mostrado que la ferritina se incrementa en presencia de una inflamación aguda o crónica (Thurnham y col, 2010). Ello dificulta el diagnóstico de ferropenia (deficiencia de hierro). La medición del RsTF se afecta menos con la inflamación y diversas publicaciones refieren que la relación [RsTf)/log [ferritina] resulta en un adecuado marcador del estatus de hierro y que no se modifica por efecto de un proceso inflamatorio. Valores $>1.5$ es indicativo de una deficiencia de hierro.
Como se aprecia en la Figura 7, a mayor nivel del Index ferritina-RsTf menor el contenido corporal de hierro. Así, valores del index $>1.5$ y Hb $<11 \mathrm{~g} / \mathrm{dL}$ en gestantes y niños menores de 5 años indica deficiencia de hierro y valores de ferritina $<30 \mathrm{ng} / \mathrm{mL}$ y $\mathrm{Hb}<11 \mathrm{~g} / \mathrm{dL}$ se define como anemia inflamatoria.

En la Figura 7 se muestra que la relación receptor soluble de transferrina/log. Ferritina es un excelente marcador del estatus corporal del hierro en el organismo. Este marcador es eficiente debido que hace una corrección del almacenaje de hierro y la inflamación. Si bien la ferritina puede censar los reservorios de hierro, esta se puede alterar si estamos frente a un proceso inflamatorio, debido que la biodisponibilidad de hierro para los hematíes disminuye y el almacenaje intracelular aumenta.

Si bien el punto de corte de $\mathrm{Hb}$ para definir anemia fue formulado por OMS y es usado extensivamente en el mundo a partir de 1968, no resulta claro cómo ha sido generado. Más bien todos los estudios tratando de evaluar valores de normalidad encuentran que el nivel de $\mathrm{Hb}$ por debajo de dos desviaciones standard en gestantes y en niños menores de cinco años se encuentra por debajo del valor de $11 \mathrm{~g} / \mathrm{dL}$ recomendado por OMS (Figura 5).

En el embarazo aumenta el requerimiento de hierro de aproximadamente 1 gramo principalmente para la placenta y el feto. Esto se consigue por un aumento en la absorción de hierro a nivel duodenal generado a su vez por la disminución en los niveles de hepcidina sérica a partir del

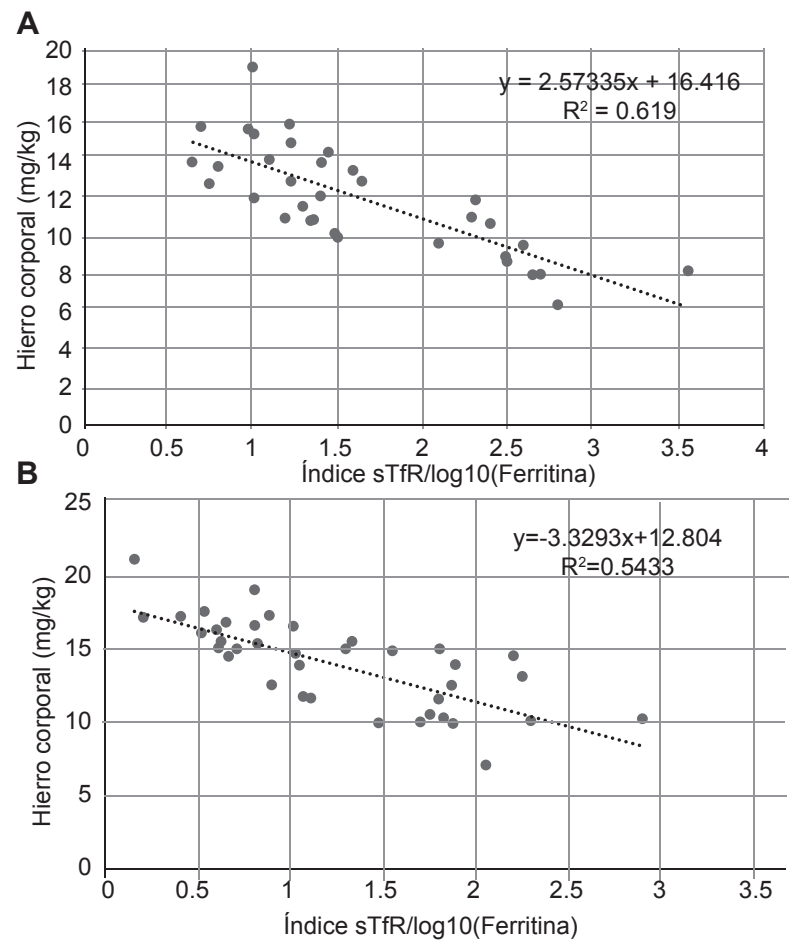

Figura 7. Relación entre el Contenido Corporal de Hierro y el Índice Receptor Soluble de Transferrina/log. Ferritina. A Mujeres y B Varones. 
segundo trimestre del embarazo. Así en el primer trimestre se requiere una absorción de $1 \mathrm{mg} /$ día y ésta aumenta a $7.5 \mathrm{mg} /$ día en el tercer trimestre (Milman, 2011).

Entre los cambios observados en el embaraø se encuentra un aumento en la masa hemática del 15-20\%, un aumento del volumen plasmático del $45-50 \%$, un aumento del volumen sanguíneo entre $35-40 \%$ y con ello una reducción en la concentración de hemoglobina a partir del segundo trimestre a pesar de la mayor eritropoyesis (Sanghavi y Rutherford, 2014). Esta disminución de la o ne ntrac ón de hemoglobina se debe entone $s$ a un proceso de hemodilución y no a una deficiencia de hierro en la dieta. La pregunta es cómo diferenciar esta "anemia" producida por hemodilución de aquella verdaderamente producida por deficiencia de hierro.

La OMS intenta compensar esta hemodilución cambiando el punto de corte de la hemoglobina para definir anemia de $12 \mathrm{~g} / \mathrm{dL}$ en no embarazadas a $11 \mathrm{~g} / \mathrm{dL}$ en embarazadas a partir del segundo trimestre. El punto de corte de $\mathrm{Hb}$ de $11 \mathrm{~g} / \mathrm{dL}$ en gestantes no toma en cuenta la capacidad de hemodiluc ón de a da gestante. Durante la gestac ón hay un aumento en la eritropoyetina (EPO) que genera una mayor eritropoyesis. Esta mayor eritropoyesis inducida por EPO se debe a una elevación en los niveles de eritroferrona y a estímulos iniciales dependientes de una caída de los niveles de hierro circulantes (Mirciov y col, 2018; Vallet, 2018). Actualmente ya se ha desarrollado un inmunoensayo para medir los niveles séricos de eritroferrona con lo que en un futuro cercano podremos conocer mejor como este marcador eritropoyético funciona en diferentes circunstancias (Ganz y col, 2017).

Se sabe que a consecuencia de la mayor eritropoyesis y para evitar que la eritrocitosis resultante pueda afectar por mayor viscosidad el flujo útero-placentario, el organismo desarrolla o mo mea nismo homeostátio la elevać ón

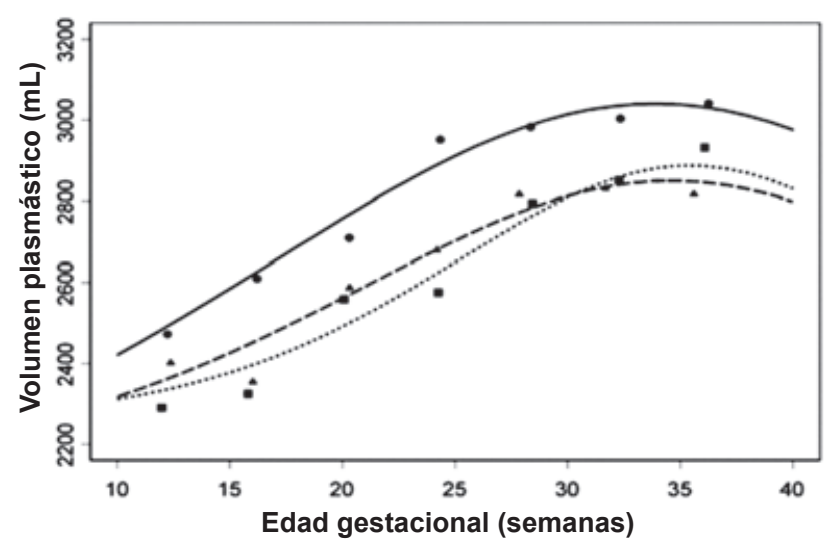

Figura 8. Cambios del volumen plasmático $(\mathrm{mL})$ en gestantes normales (línea negra), gestantes con preeclampsia (línea punteada) y gestaciones complicadas con restricción en el crecimiento fetal (línea entre cortada). En las gestantes con preeclampsia o fetos con restricción en el crecimiento muestran hemoo ne ntracín. del volumen plasmático (Figura 8). Como se puede ver en la figura 8, el aumento del volumen plasmático no tiene la misma magnitud en todas las gestantes. En efecto las gestantes con pre-eclampsia y en aquellas con niños con restric ón en el $\mathrm{c}$ éc miento uterino muestran menores valores de volumen plasmático (hemoconcentración) elevando o $\mathrm{n}$ ello la o ne ntrac ón de hemoglobina.

Con solo la medición de hemoglobina no es posible determinar si estamos frente a una situación de hemodilución normal o realmente frente a una anemia. En base a estudios asoic ando los niveles de hemoglobina en gestantes con parámetros clínicos muestran que gestantes con $\mathrm{Hb}$ menor $11 \mathrm{~g} / \mathrm{dL}$, pero con volumen corpuscular medio normal deben ser o nsideradas normales y no anémicas (Steer, 2005).

Los cambios hemodinámicos que ocurren en el embarazo son de suma importancia pues permiten por un lado mejorar el flujo útero placentario proporcionando con ello los requerimientos de oxígeno y nutrientes al feto y proteger a la gestante de los efectos negativos que pueda tener la pérdida de sangre durante la labor de parto y el parto.

Aunque los diferentes centros en el mundo usan el punto de corte de $\mathrm{Hb}$ de $11 \mathrm{~g} / \mathrm{dL}$ para definir anemia en los tres trimestres de gestación, existen referencias científicas que los puntos de corte considerados son $11 \mathrm{~g} / \mathrm{dL}$ en el primer y tercer trimestre y $10.5 \mathrm{~g} / \mathrm{dL}$ en el segundo trimestre (Milman, 2008). Las guías del Colegio Americano de Obstetras y Ginecólogos (ACOG) y del Comité Británico para Standards en Hematología define anemia en el embarazo cuando los valores de $\mathrm{Hb}$ son $<11$ $\mathrm{g} / \mathrm{dL}$ en el primer trimestre $\mathrm{y}<10.5 \mathrm{~g} / \mathrm{dL}$ en el segundo $\mathrm{y}$ tercer trimestre (Muñoz y col, 2018).

Con el avane en el o noć miento de la homeostasis de hierro queda claro que la sola medición de $\mathrm{Hb}$ es insuficiente y que se hace necesario tener un conteo de glóbulos rojos que ahora se obtiene fácilmente con los equipos automatizados, la medición en suero de los niveles de ferritina y del receptor soluble de transferrina, así como un marcador de inflamación como la proteína $C$ reactiva, la alfa glicoproteína ácida AGP, o los niveles de interleukina 6 y de interleukina 8.

Se considera que mujeres con niveles de ferritina $<15$ $\mathrm{ng} / \mathrm{mL}$ tienen reservas de hierro agotadas (deficiencia de hierro) y por lo tanto debería recibir hierro en forma terapéutica (Milman, 2011). Aunque no es claro como se ha determinado el punto de corte de $\mathrm{Hb}$ de $11 \mathrm{~g} / \mathrm{dL}$ para definir anemia es recomendable que para obtener un valor confiable, éste debería estar basado en una población de mujeres sanas repletas en hierro corporal así como de niveles repletos de folato y vitamina $\mathrm{B} 12$, que tienen un embarazo único y un parto único.

En 1989, la OMS define la magnitud de anemia como leve ( $\mathrm{Hb} 10-10.9 \mathrm{~g} / \mathrm{dL})$, moderada ( $\mathrm{Hb} 7-9.9 \mathrm{~g} / \mathrm{dL}$ ) y severa 



Figura 9. Interrelación entre hemoglobina, ferritina y receptor soluble de transferrina. Esquema adaptado para infantes. Cuando los niveles de ferritina sérica disminuyen por debajo de $12 \mathrm{ng} / \mathrm{mL}$ se observa ferropenia, la hemoglobin aún se mantiene normal, si el proceso continua hay anemia ferropénica cuya magnitud aumenta conforme aumentan los niveles del receptor soluble de transferrina. Para la gestante se considera como punto de corte para ferropenia un nivel de ferritina sérica de $15 \mathrm{ng} / \mathrm{mL}$.

$(\mathrm{Hb}<7 \mathrm{~g} / \mathrm{dL})(\mathrm{WHO}, 2011)$. La OMS considera que previo a la presencia de anemia leve ya existe una deficiencia de hierro con aún valor normal de hemoglobina (Figura 9). Diversos estudios han mostrado que en el rango de anemia leve se observan los mejores parámetros reproductivos para la madre y el feto (Gonzales y col, 2009; Little y col, 2005; Steer, 2000; Buzyan y col, 2015; Bencaiova y Breymann, 2014). Estos datos sugieren que la deficiencia de hierro, y la anemia leve con deficiencia de hierro no afectarían la salud de la madre ni del feto. Sin embargo, es necesario evaluar otros parámetros clínicos antes de generalizar este concepto.

Un mayor riesgo para muerte fetal tardía y mortalidad perinatal se observa recién en rangos de anemia moderada y severa (Nair y col, 2017; Räisänen y col, 2014; Kozuki y col, 2012).

Otro aspecto que no se ha re-evaluado es el ajuste de $\mathrm{Hb}$ por la altura la cual se basa en una ecuación matemática desarrollada por CDC de Atlanta. Este ajuste es matemático y no basado en ninguna definición clínica. Más aun basado en parámetros clínicos, la tasa más baja de pequeño para edad gestacional ocurre entre 9-10 $\mathrm{g} / \mathrm{dL}$ de $\mathrm{Hb}$, tanto a nivel del mar como en altura y la tasa aumenta conforme aumenta el valor de $\mathrm{Hb}$, siendo los más altos sobre $14.5 \mathrm{~g} /$ $\mathrm{dL}$. Adicionalmente se tiene el hecho que esta norma al ser universal no es posible aplicarse a todas las poblaciones que habitan en zonas de altura. En efecto, los Tibetanos en Los Himalayas que tienen mayor antigüedad generacional, presentan menos concentración de hemoglobina que los Han, que solo residen allí no más de 70 años.

Igualmente en Perú, las poblaciones del sur del Perú, en particular los Aymaras de Puno presentan una mayor antigüedad generacional que los Quechuas. Se ha demostrado en estas poblaciones Aymaras que los niveles de hemoglobina son más bajos que los observados en poblaciones que habitan zonas de igual altitud pero con menor tiempo generacional (Gonzales y col, 2011)

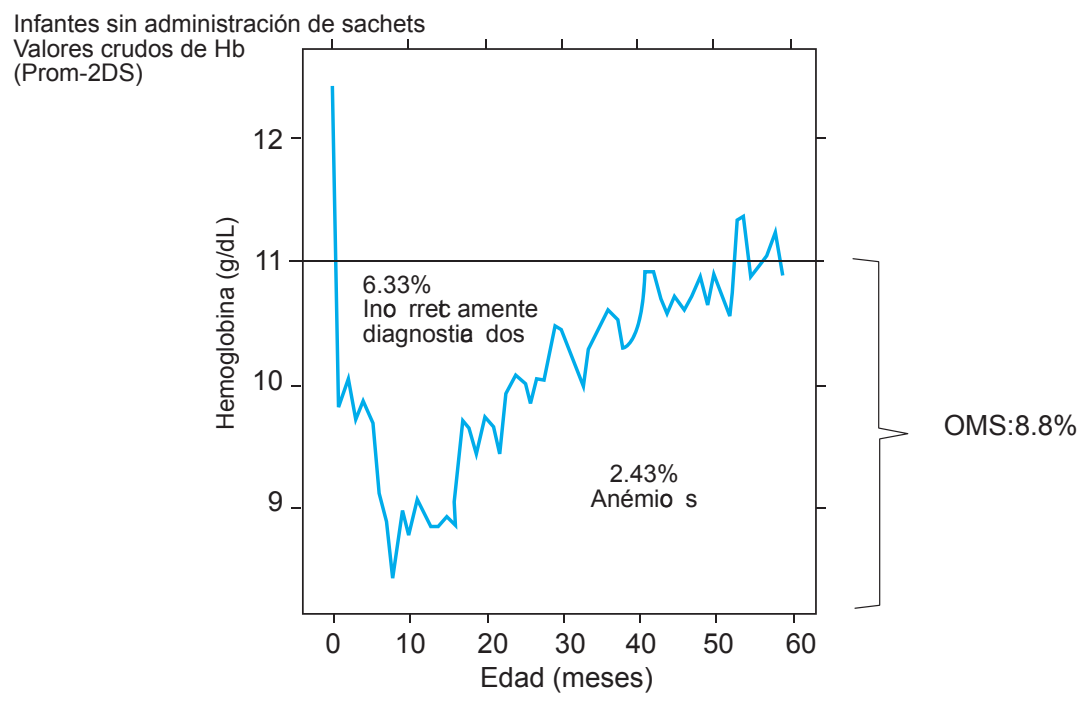

Figura 10. Punto de corte de la hemoglobina basado en menos dos desviaciones standards (-2DS) en población de niños peruanos de 0 a 59 meses. $6.33 \%$ de los niños estudiados caen por debajo del punto de corte definido por OMS (Hb: $11 \mathrm{~g} / \mathrm{dL}$ ). 



- Nacional _ EE.UU

Figura 11. Valores medios y de menos dos desviaciones standard de hemoglobina en niños de Estados Unidos (A) y de Perú (B) menores de 60 meses. Valores medios de $\mathrm{Hb}$ en niños de Estados Unidos y de Perú (C).

\section{Evidencias para re-definir los puntos de corte definidos por OMS para infantes y gestantes}

Los valores de $\mathrm{Hb}$ caen dramáticamente luego del nacimiento por el pasaje de una vida en ambiente hipóxico a otro normóxico (Figura 10,11). Estos cambios no determinan cambios en el contenido de hierro pues el hierro del eritroc to destruido luego del nac miento se almacena como ferritina mientras la hemoglobina se reduce. Esta conversión debe ser progresiva, ya que la hemoglobina fetal tiene una afinidad mayor $\mathrm{al}_{2} \mathrm{O}_{2}$, ya que en el medio hipóxico el feto necesita suplir su requerimiento de ox́ geno. Luego del nać miento y al inc ementarse los niveles de $\mathrm{Hb} \mathrm{A}$ la afinidad disminuye. Igualmente la saturación arterial de oxígeno que es baja al nacer tanto a nivel del mar y mucho más bajo en la altura, incrementa luego del parto (Gonzales y Salirrosas, 2005).

Tanto en gestantes como en niños menores de 5 años, los valores de normalidad definidos como media-2DS caen por debajo del límite determinado por OMS para definir anemia $(\mathrm{Hb}=11 \mathrm{~g} / \mathrm{dL})$, aumentando de manera incorrecta la tasa de anemia, particularmente entre 6 y 36 meses de edad (Figura 12).

Los valores medios de hemoglobina son similares para Perú que para una muestra en Estados Unidos (Figura 11). Los valores de normalidad aumentan progresivamente

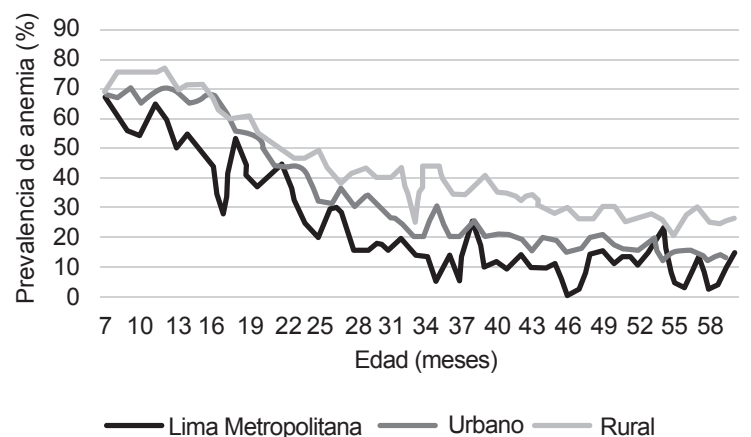

Figura 12. Prevalencia de anemia en zona rural, resto urbano y de Lima Metropolitana en niños entre 6 y 59 meses (Fuente: ENDES)

de 3 a 6 años disminuyendo en esa etapa de la niñez la prevalencia de anemia (Figura 12).

Como una manera de determinar el grado de patología que genera la anemia definida según lo que recomienda OMS, se observa en la Figura 13 que clínicamente la menor tasa de desnutrición crónica se observa en niños en el rango de anemia leve.

Igualmente en gestantes, los menores valores de Pequeño para edad gestacional, muerte fetal tardía, preeclampsia y 


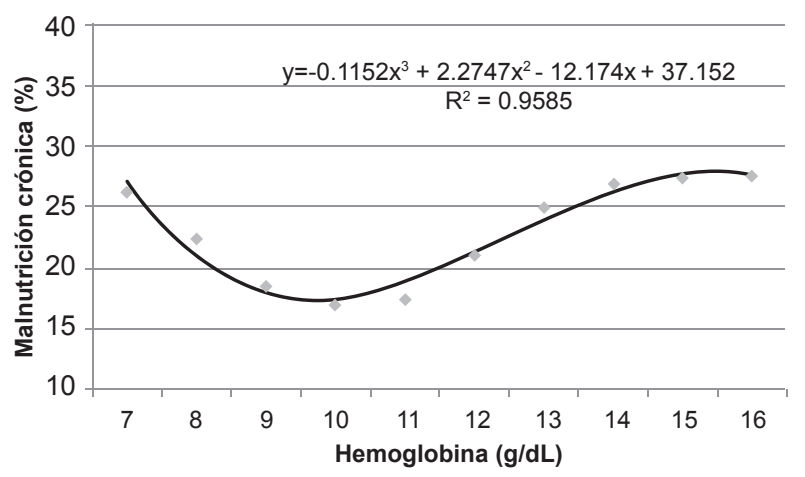

Figura 13. Prevalencia de desnutrición crónica basada en Z-score de talla por edad en niños peruanos menores de 60 meses.

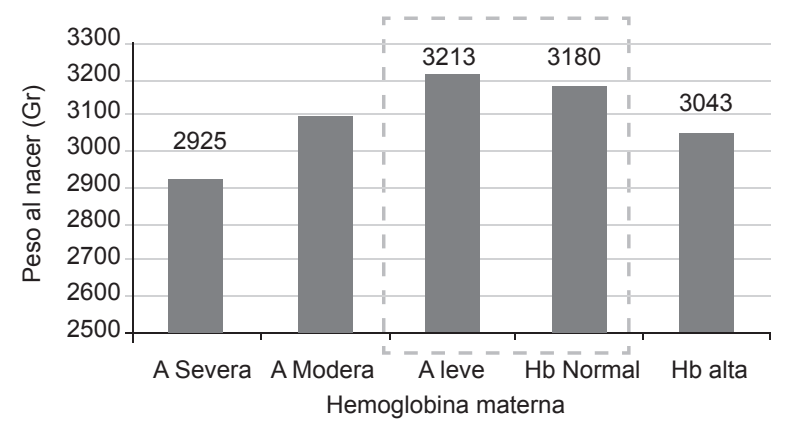

ANOVA $p<0.001$

Figura 14. Peso del recién nacido según valor de hemoglobina materna. Las medias más altas de peso al nacer se observa en el rango de anemia leve (Fuente propia).

mortalidad materna se ena entran en el rango de anemia leve. En la Figura 14 el mayor peso al nacer se observa en el rango de anemia leve. Hemoconcentración en el segundo y tere $r$ trimestre de gestac ón debido a un menor aumento del volumen plasmático se asocia a preeclampsia (Khoigani y col, 2012).

\section{Corrección de la Hemoglobina por la Altura}

La OMS y la CDC de Atlanta corrigen el punto de corte de la hemoglobina en los pobladores a partir de los 1000 $\mathrm{m}$ de altura. Esta corrección se basa en la premisa que la concentración de hemoglobina se incrementa conforme aumenta la altitud de residencia. Este patrón, sin embargo, no es universal pues no se cumple entre los Tibetanos en los Himalayas, ni entre los Aymaras en los Andes del Sur del Perú. Estas poblaciones adecúan un mejor transporte de oxígeno a las células con menor concentración de $\mathrm{Hb}$ y una maø $r$ saturać ón arterial de óx geno.

Se asume al hacer la corrección de la Hb por la altura, de que existe concomitantemente una deficiencia de hierro, al establecerse que en base a esta corrección, la prevalencia de anemia se incrementa en la altura. Nuestros estudios de investigación, sin embargo, no avalan estas suposiciones. Por el contrario, el contenido de hierro es mayor en la altura que a nivel del mar. $\mathrm{Si}$ se corrige la hb por la altura, baja la $\mathrm{Hb}$ pero sigue

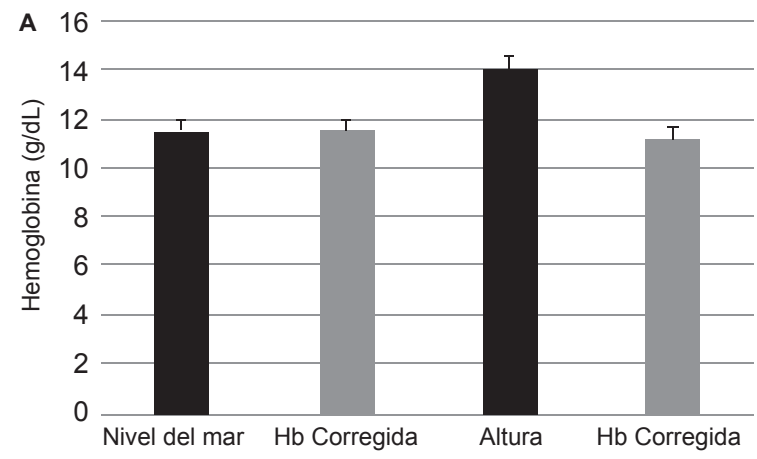

B

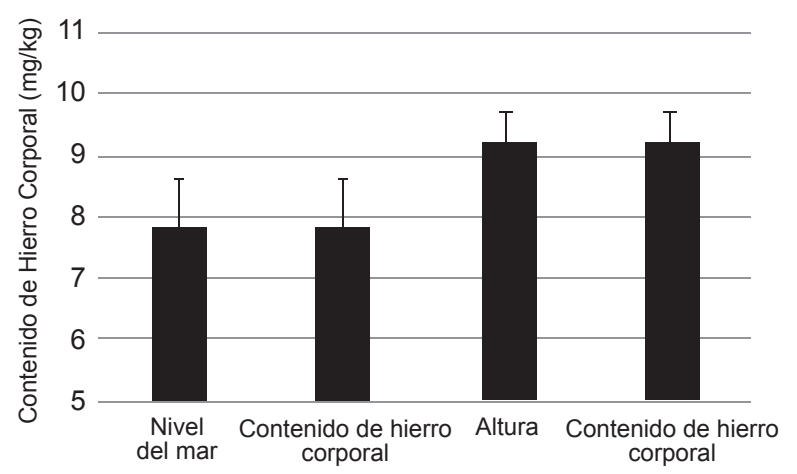

Figura 15. Estatus de hierro o $\mathrm{n}$ y sin o rrec ón de hemoglobina por altura en adultos. Luego de ajustar la hemoglobina en Cerro de Pasco (4340 m), el valor se asemeja al promedio de Lima (150 m) (A), sin embargo el contenido de hierro es mayor en Cerro de Paso que en Lima (B).

A

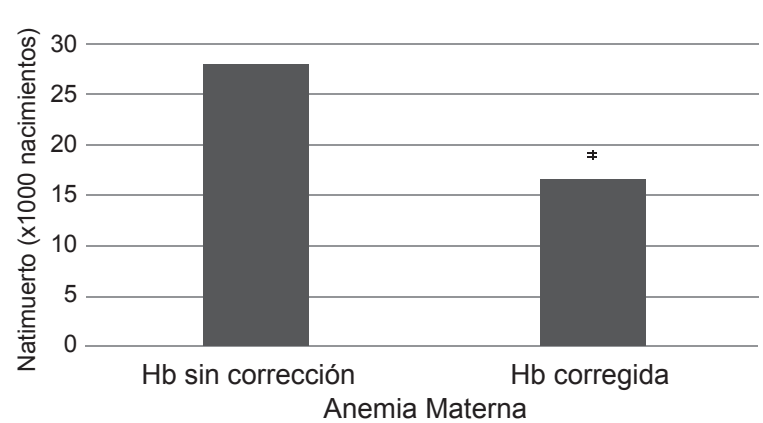

B

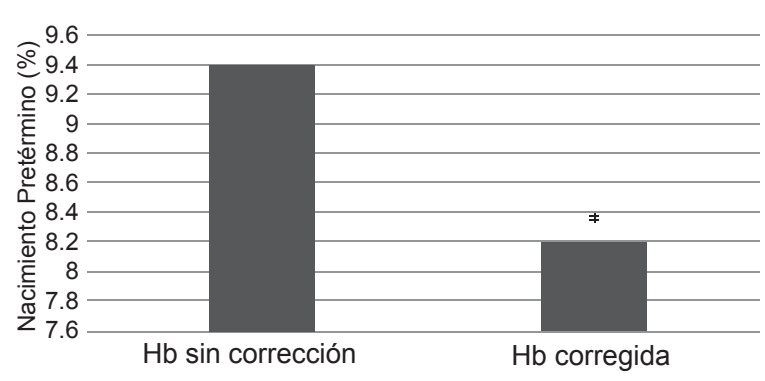

Anemia Materna

Figura 16. La corrección de la Hemoglobina por la altura disminuye la tasa de muerte fetal tardía $(\mathbf{A})$ y de pre-términos $(\mathbf{B})$ indicando que los anémicos calificados luego de la corrección no son realmente anémicos . $A^{*} p<0.001 ; C^{*} p<0.001$. Modelo de regresión logística ajustado por edad, IMC, educación materna, paridad, preeclampsia e infección urinaria. Fuente: Gonzales y col, 2014. 
elevado el contenido de hierro (Figura 15). En este caso el tratamiento con hierro oral será inefectivo, a pesar que las cifras de prevalencia de anemia por uso de $\mathrm{Hb}$ corregida por la altura se mantengan altas. La Figura 16 nos muestra que la corrección de $\mathrm{Hb}$ por altura reduce en los diagnosticados como anémicos las tasas de partos pretérmino o muerte fetal tardía indicando que los nuevos diagnosticados como anémicos por la corrección no lo son.

\section{ESTATUS DE HIERRO EN LA ALTURA}

El nivel de hepcidina es un marcador de la disponibilidad de hierro en el organismo. En el embarazo, los niveles séricos de hepcidina disminuyen en el segundo trimestre con la finalidad de aumentar en el duodeno la absorción del hierro (Gonzales y col, 2017). Los niveles de hepcidina sérica en gestantes de la altura de Ayacucho fueron similares a los de nivel del mar (Lima) (Gonzales y col, 2017). Lo anterior sugiere que el estatus de hierro en la altura es similar al de nivel del mar.

Como una manera de determinar si el factor de corrección de la $\mathrm{Hb}$ por la altura es realmente necesario, se ha utilizado la generación de curvas ROC (Receiver Operating Characteristics) comparando tres ecuaciones de regresión teniendo como variable dependiente la anemia definida sin corrección de la $\mathrm{Hb}$ por altura, y la anemia definida usando dos ecuaciones diferentes de corrección de la $\mathrm{Hb}$ por altura. Una es cuadrática que es la recomendada por CDC y que es utilizada por el Ministerio de Salud del Perú. La segunda es una recientemente desarrollada basada en una ecuación exponencial y descrita por Bartolo y col (2017), y que ha sido presentado en un evento por el MINSA en enero del 20'18. La curva ROC de la anemia no corregida en a altura es significativamente mayor que usando la curva ROC de anemia modificada propuesta por CDC de Atlanta o por ecuación de Bartolo propuesto por MINSA en 2017 (Gonzales y col, enviado a publicación).

Uno de los criterios para la suplementación con hierro es que hay deficiencia de hierro en la dieta. Esto no se corrobora con nuestros estudios donde se ha demostrado que el consumo de hierro en adultos es mayor en dos poblaciones en la altura que en una a nivel del mar (Figura 17).

\begin{tabular}{lccc}
\hline Lugar & Fe-Heme & Fe-No heme & $\mathbf{P}$ \\
\hline Paso (51) & $3.53 \pm 0.34^{* *}$ & $14.07 \pm 0.83^{*}$ & $<0.001$ \\
\hline Puno (50) & $3.21 \pm 0.32$ & $13.18 \pm 0.56^{*}$ & $<0.001$ \\
Lima (46) & $2.38 \pm 0.43$ & $8.96 \pm 0.46$ & $<0.001$ \\
\hline
\end{tabular}

Figura 17. Consumo de hierro heme y no heme en mujeres de nivel del mar y de la altura. Los datos son medias $\pm E E$. El número de mujeres se encuentra entre paréntesis. ${ }^{*} p<0.01 ;{ }^{* *} p<0.05$ con respecto a Lima.

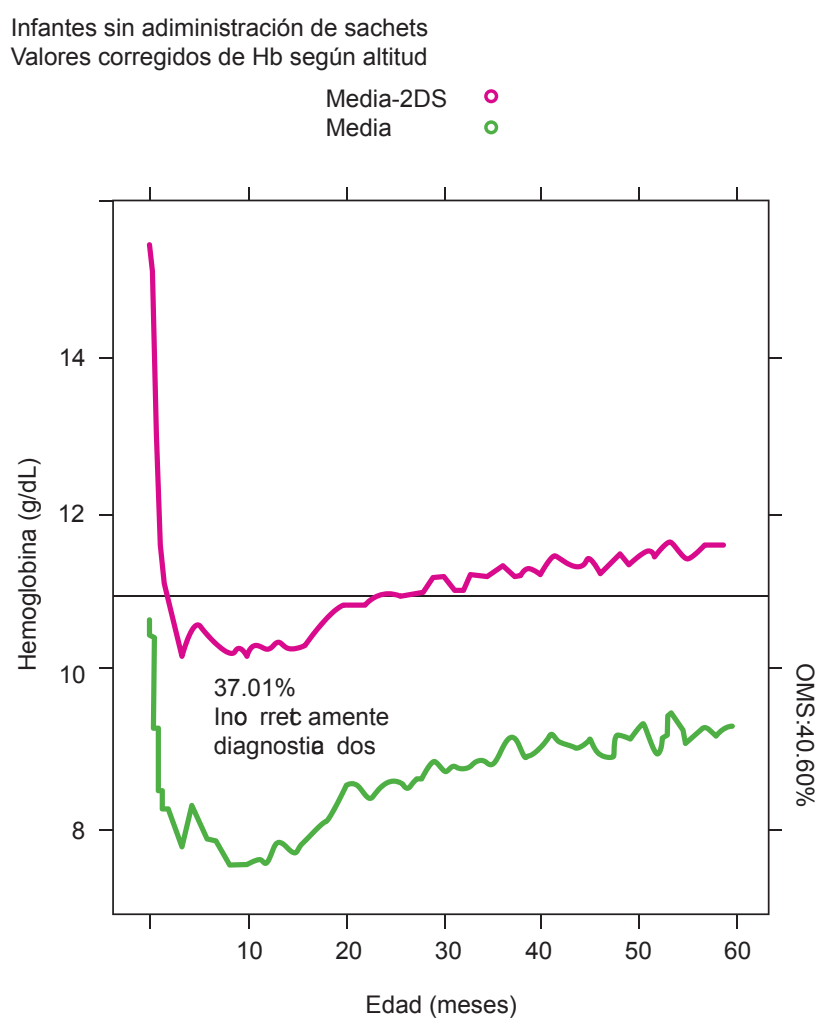

Figura 18. Después de la corrección de la hemoglobina por la altura, la prevalencia de anemia sube de $8.8 \%$ a $40.6 \%$ de los cuales $37.01 \%$ son diagnosticados incorrectamente al no coincidir el punto de corte de OMS con los valores de menos dos desviaciones standard de la población estudiada.

La corrección de hemoglobina por la altura en menores de 60 meses aumenta la prevalencia de anemia de $8.8 \%$ (Figura 10) a $40.60 \%$ (Figura 18). El uso de punto de corte de $11 \mathrm{~g} / \mathrm{dL}$ genera un $37.01 \%$ de diagnóstico incorrecto de anemia (Figura 18).

La adaptación de poblaciones con más tiempo de residencia en altura, no incrementan sus niveles de hemoglobina, sino tienden a ser menores que los observados en sujetos con menor tiempo generacional en la alturas. Los Aymaras han pasado por un proceso de adaptación mayor que los Quechuas y otras poblaciones, por lo que sus valores de hemoglobina son más bajos, es por ello que si ajustamos con el punto de corte la prevalencia de anemia es mayor para ellos. En el caso de los de descendencia hispana, la mayor cantidad viven a nivel del mar en donde el punto de corte de hemoglobina no les afecta (Figura 19).

Esta mayor adaptación de la población de Puno se aprecia en las Figuras 20 y 21 . El nivel de hemoglobina materna es más baja en Puno a $3800 \mathrm{~m}$ de altura que en Huancavelica ubicado incluso a menor altitud. Una menor tasa de muerte fetal tardía se observa en Puno que en otras zonas de similar altitud pero de menor 


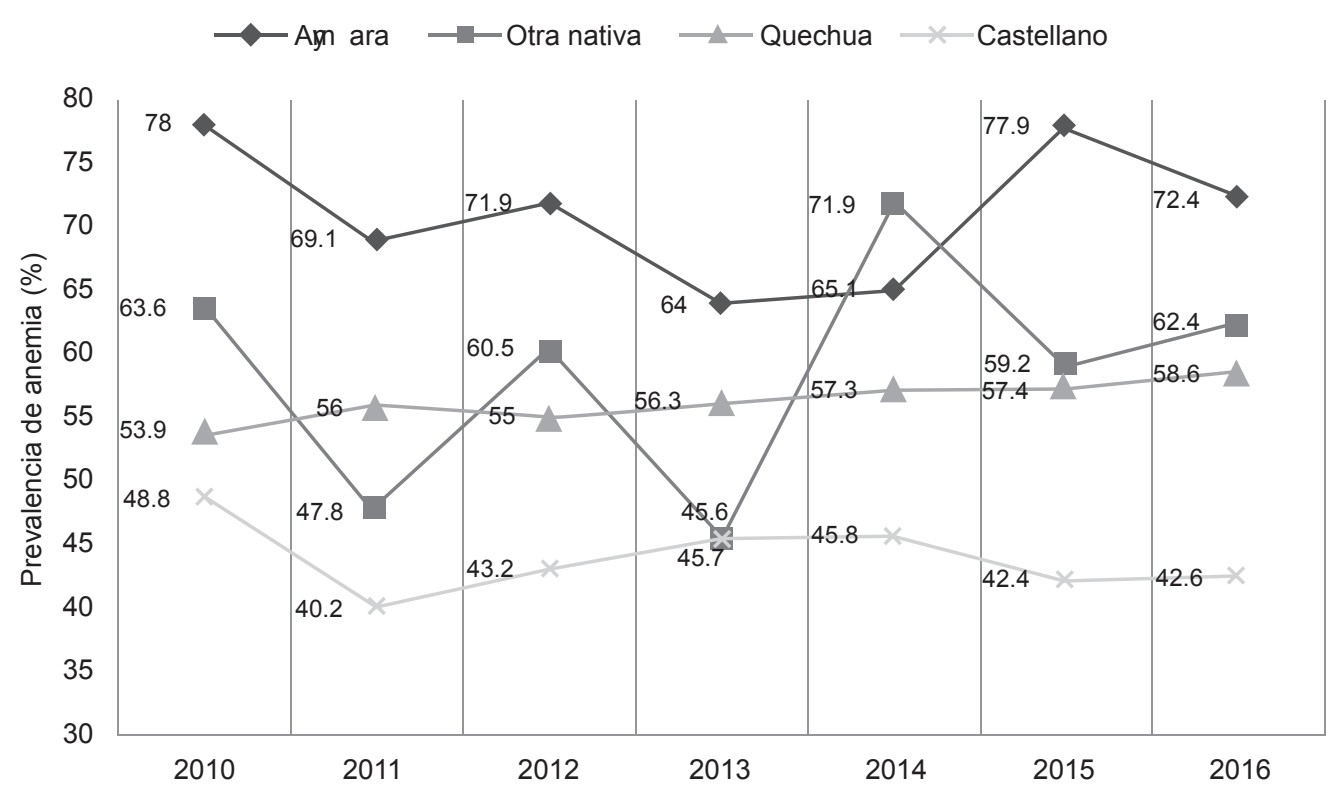

Figura 19. Prevalencia de anemia en niños de 6 a 35 meses de edad según su lengua materna (Fuente: MIDIS).

A $\longrightarrow$ Puno $\rightarrow$ Huancavelica

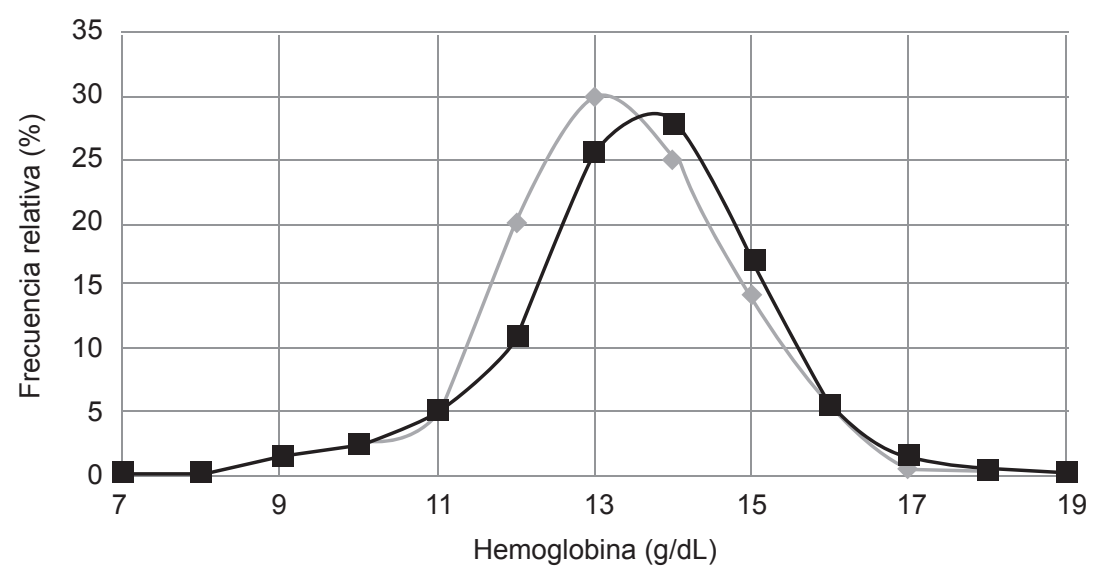

B

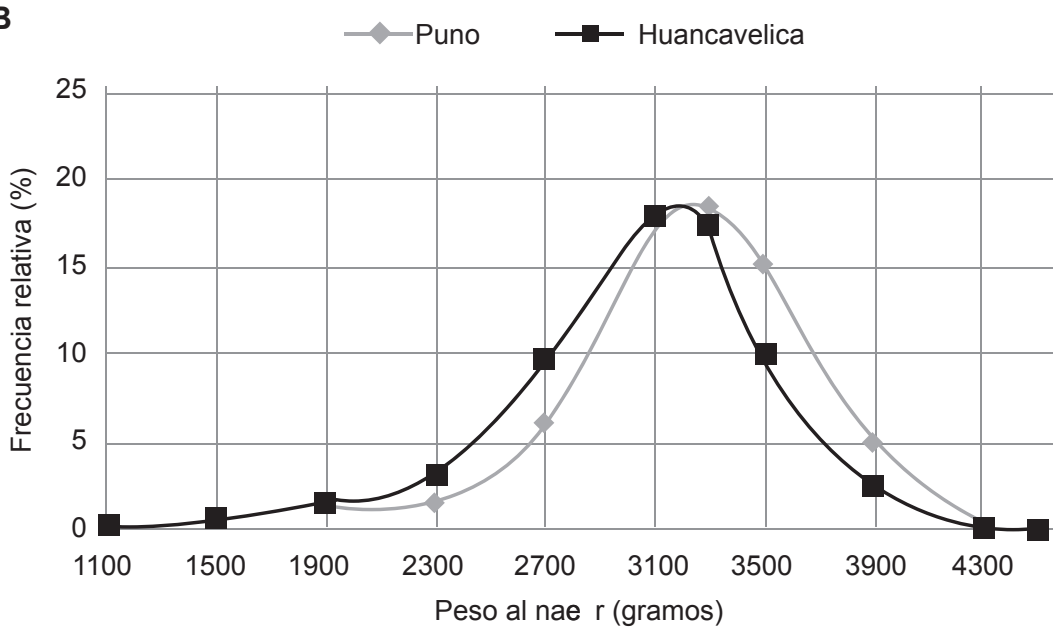

Figura 20. A Distribución de la hemoglobina materna en Huancavelica (3600 m) y Puno (3800 m). B Distribución del peso al nacer en Huancavelica $(3600 \mathrm{~m})$ y Puno (3800 m). 


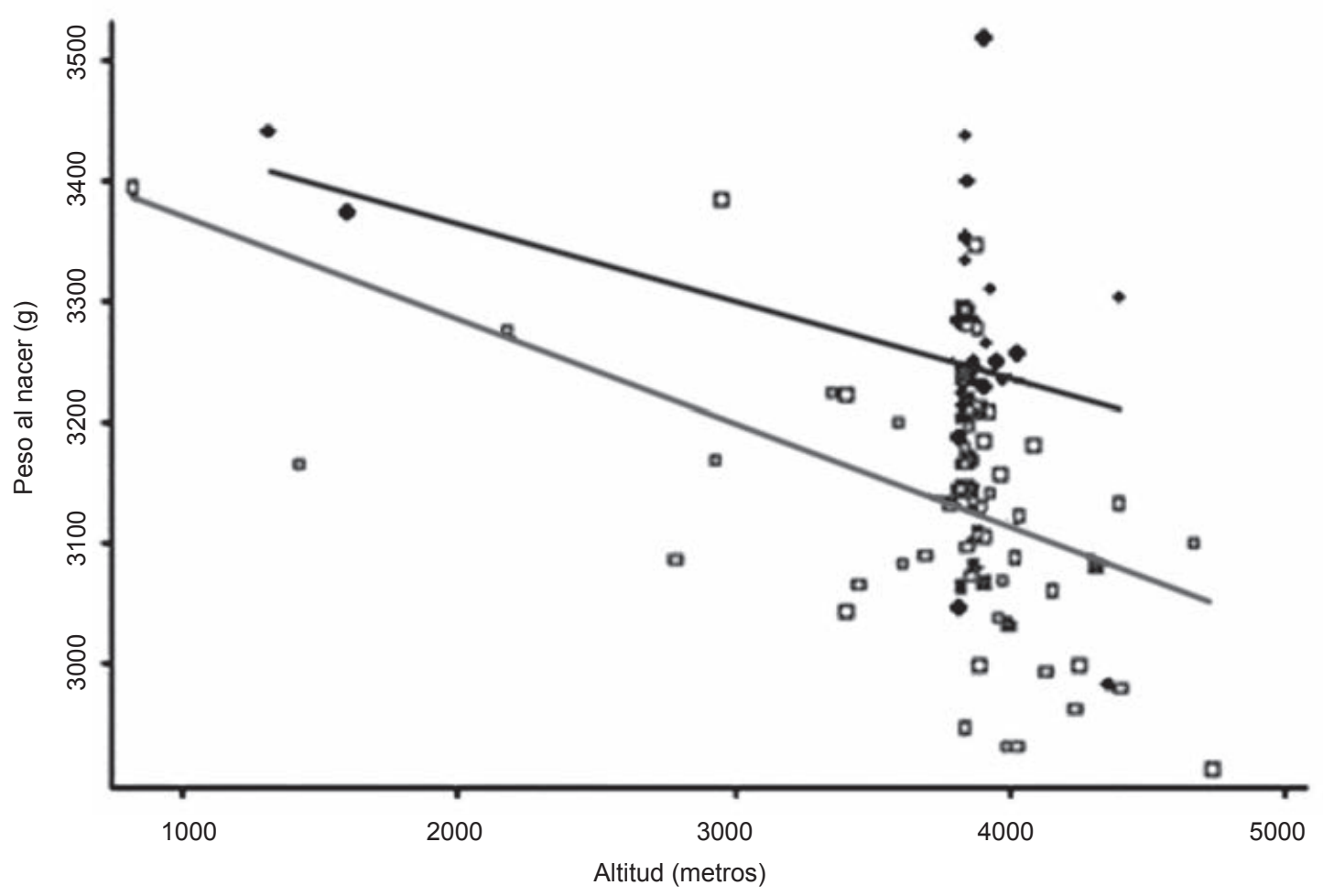

Figura 21. Peso al nacer según altitud en distritos de Puno con mayor $50 \%$ de ascendencia Aymara (rombos) o con menor de $50 \%$ de ase ndenc a Am ara (a adrados).

antigüedad generacional en la altura (Gonzales y col, 2008). Del mismo modo el peso del recién nacido es mayor en las poblaciones con mayor componente Aymara (Figura 21). Estos datos determinan que el efecto de la corrección de la $\mathrm{Hb}$ por la altura afecten mucho más a la población de Puno que a otras poblaciones que viven en la altura.

\section{Anemia de Inflamación}

La anemia de inflamación o anemia de enfermedades crónicas es una anemia normocítica, normocrómica causada por una enfermedad inflamatoria. Se le diagnostica cuando los niveles de hierro sérico son bajos acompañados de niveles altos de ferritina sérica. Cuando hay una inflamación es difícil diferenciar entre anemia inflamatoria de la anemia por deficiencia de hierro; más aún cuando ambas coexisten (Nemeth y Ganz, 2014).

La anemia de inflamación resulta de una defensa del huésped para evitar la supervivencia de microorganismos patógenos. En este proceso, las citoquinas inflamatorias acortan la vida de los eritrocitos debido a la activación de macrófagos, favoreciendo la producción leucocitaria en la médula ósea, que a su vez se traduce en un aumento de hepcidina la cual aumentará la saturación de transferrina y la concentración de hierro unido a ferritina (Ganz, 2018).
En la actualidad es ampliamente reconocido que la anemia, la inflamación y el stress oxidativo se encuentran interconectados (Sharma y Puri, 2018). Si bien se conoce que la inflamación eleva los niveles de hepcidina y esta elevaćón o ndue a una disminucón de la absorcón de hierro desde el duodeno o su liberac ón de las $\square$ nas de su almacenaje, recientemente se ha observado que eritrocitos que han sido dañados por stress oxidativo son fagocitados por los mastocitos (Sharma y Puri, 2018) o nvirtiéndose en otro mea nismo de desarrollo de anemia frente a la inflamación.

En las enfermedades infecciosas, el hierro juega un doble papel, uno como modulador de la respuesta inmune innata y la segunda como nutrientes para los microbios (Nairz y col, 2018). El organismo para defenderse de los microbios reduce su disponibilidad de hierro aumentando los niveles de hepcidina (Karaskova y col, 2018). La malaria es una patología frecuente en nuestra selva. Los casos de malaria se asocian con niveles altos de ferritina. Por ello, se están realizando esfuerzos en la investigación de casos de malaria en presencia de anemia del embarazo con deficiencia de hierro (IDA)(Bahizire y col, 2018). La prevalencia de anemia en la selva es alta pero no se asocia a bajo peso al nacer debido a que la mayor parte es calificada como anemia leve (Becerra y col, 1998).

En un estudio en gestantes obesas se ha observado niveles altos de hemoglobina y conteo de leucocitos 
en el embarazo temprano (Elmugabil y col, 2017). Este efecto asociado con obesidad en gestantes es opuesto a la esperada anemia por obesidad. Esto ha sido confirmado en un estudio en nuestro laboratorio donde se presume que el aumento de $\mathrm{Hb}$ se debe a una hemoconcentración y que estaría asociada a una menor ganancia de peso durante el embarazo (Olavegoya y Gonzales, no publicado). Estudios con la medición de ferritina muestran que las gestantes obesas presentan deficiencia de hierro asociado a bajos valores de ferritina sérica (Abbas y col, 2017).

Actualmente se conoce que los procesos inflamatorios no asociados a infecciones también tienen un efecto favoreciendo la producción de anemia. En resumen, la fisiopatología de la anemia inflamatoria es multifactorial y resulta de un efecto de citokinas inflamatorias que tanto directa como indirectamente van a suprimir la eritropoyesis. La citokina inflamatoria interleukina 6 (IL-6) aumenta los niveles de hepcidina y con ello disminuye el hierro sério aumentando el sea estro de hierro en los tejidos de almacén y disminuye la absorción duodenal de hierro (Langer y Ginzburg, 2017).

El embaraø también es o nsiderado o mo un estado inflamatorio, sin embargo no se sabe en qué medida la anemia inflamatoria en el embarazo afecta la salud del neonato. Un reciente estudio ha mostrado que la anemia en el embarazo por deficiencia de hierro pero no por anemia inflamatoria se asocia con menores reservas de hierro en el neonato (Abioye y col, 2018).

\section{Intervención contra la anemia}

Los programas de intervención contra la anemia tienen más de 50 años. En el Perú tienen más de dos décadas, inicialmente orientadas a las gestantes, donde la norma del MINSA indica la obligatoriedad de suplementar con hierro a todas las gestantes sean anémia $\mathrm{s}$ o no. En el caso de los niños menores de 5 años, el programa de intervención masiva tiene aproximadamente cinco años. En Junio 2018, una norma del Gobierno Peruano manda suplementar con hierro a niños de 36 a 59 años sean o no anémicos, con la finalidad de prevenir la anemia.

De acuerdo a los últimos conocimientos sobre homeostasis de hierro, no es posible tener una intervención de carácter preventivo a personas con suficiencia de hierro. De acuerdo al sistema de regulación por hepcidina, cuando hay suficiencia de hierro en el organismo, el nivel de hepcidina sérica será el suficiente para lograr una absorción de $1 \mathrm{mg}$ de hierro/día. Todo exceso de hierro que no se pueda absorber por la suficiencia de hierro, será eliminado por las heces.

De au erdo a las normas de tratamiento en los a sos de anemia, los programas están basados casi en su totalidad de suplementar con hierro. Se sabe sin embargo que en poblaciones donde las inflamaciones producidas por infecciones es prevalente como ocurre en la selva del Perú, la intervención con suplemento oral de hierro será inefectivo hasta no desaparecer la inflamación.

De lo anterior se deduce que la sola medición de la concentración de hemoglobina no será útil para derrotar la anemia en el Perú. Los programas de lucha contra la anemia deben incluir la medición de hemoglobina, el hemograma, al menos un marcador de estatus de hierro, y un marcador de inflamación. La medición de hepcidina es de mucho valor pero aún requiere ser standarizado para determinar cuándo se encuentra elevado por suficiencia de hierro o por presencia de inflamación y cuál es el nivel inferior a partir del cual podemos afirmar que hay un requerimiento de hierro. La valoración de folatos, homocisteína, vitamina $A$, Vitamina B12 (Zaric y col, 2018) será necesaria cuando se sospechen que la anemia es producida por otro factor y no por la deficiencia de hierro. Es necesario determinar la etiología de la anemia para tener claro cuál será la intervención.

La anemia moderada y severa son situac ones que comprometen la salud y hasta la vida principalmente en niños y en gestantes por lo que es importante su tratamiento. Es importante también valorar la eritrocitosis que no es tan infrecuente de acuerdo a los estudios realizados en nuestro país en particular en poblaciones residentes en las alturas.

En mub os a sos la intervencín ón hierro oral resulta inefectiva. Por ello se han descrito otras formas terapéuticas o mo la administrac ón endovenosa de a rbox maltosa férrica (Breymann y col, 2017). Este tratamiento puede ser adea ado en a sos de anemia severa que es una causa importante de mortalidad materna por hemorragia uterina post-parto.

La lactoferrina, una glicoproteína secretada por glándulas exocrinas y neutrófilos, también ha sido sugerida para el tratamiento oral comparado con el efecto de la infusión de hierro dextrano de bajo peso molecular (Darwish y col, 2018). La lactoferrina además de poseer hierro, tiene un componente anti-inflamatorio. Incluso la lactoferrina ha sido sugerida para reemplazar al sulfato ferroso mostrando menos efectos colaterales (Abu Hashim y col, 2017).

En gestantes con anemia inflamatoria se ha mostrado que la lactoferrina bovina disminuye los niveles de IL-6 y aumenta parámetros hematológicos como la hemoglobina. Este efecto parece ser independiente a un efecto del hierro de la lactoferrina (Rosa y col, 2017)

La deficiencia de vitamina B12 puede generar desórdenes neurodegenerativos importantes en infantes que pueden ser observados en niños de madres con anemia perniciosa (Papp y col, 2017). 
Hay aún discrepancia sobre el suplementar con hierro a gestantes y niños no anémicos. Algunos autores sugieren no suplementar a gestantes no anémicas (steer, 2013). Otros autores como Krafft, (2013) se basan en una revisión Cochrane (Peña Rosas y col, 2012) que encuentra que la suplementación prenatal diaria con hierro reduce el riesgo de bajo peso y previene la anemia materna y la deficiencia de hierro. Sin embargo, el efecto sobre la gestación y el neonato, incluyendo una mejora en el peso al nacer no es corroborado en la actualización realizada en 2015 (Peña-Rosas y col, 2015). Más aún el riesgo de $\mathrm{Hb}$ elevada $(\mathrm{Hb}>13 \mathrm{~g} / \mathrm{dL})$ aumenta con la suplementación con hierro (Peña-Rosas y col, 2015). Una revisión sistemática en 67 ensayos de 76 reportes mostraron en general que la suplementación diaria con hierro reduce la prevalencia de anemia y la de deficiencia de hierro, eleva los niveles de hemoglobina y las reservas de hierro, mejora el rendimiento ante el ejercicio y reduce la fatiga sintomática. No muestran sin embargo una mejora en el rendimiento cognitivo, y por el contrario aumentan los efectos colaterales a nivel de Tracto gastrointestinal (Low y col, 2016). Cuando se aplica suplementación de hierro a adultos deficientes de hierro pero no anémicos, una revisión sistemática en 1170 sujetos muestra que la intervenc ón aumenta los niveles de hemoglobina y de ferritina sérica y se asocia con reducción en las mediciones subjetivas de fatiga pero no en mejoras objetivas de capacidad física (Houston y col, 2018).

En conclusión, las evidencias sugieren que el ajuste de hemoglobina por la altura es innecesario y aumenta de manera significativa la prevalencia de anemia en poblaciones en particular mayores de 3000 metros de altura. Se debe redefinir el punto de corte de $\mathrm{Hb} 11 \mathrm{~g} /$ $\mathrm{dL}$ para diagnosticar anemia en niños menores de 60 meses y en gestantes. Se deben de o nsiderar evaluar el contenido de hierro corporal y otros biomarcadores del hierro, siempre ajustándolos por el aporte inflamatorio, de esta manera podemos distinguir exactamente la prevalencia de anemia por deficiencia de hierro, excluyendo los demás tipos.

\section{Financiamiento: Autofinanciado.}

Conflicto de interés: Los autores declaran no tener algún conflicto de intereses.

\section{REFERENCIAS BIBLIOGRÁFICAS}

1. Abbas W, Adam I, Ray s DA, Hassan NG, Lutfi MF. Higher Rate of Iron Deficiency in Obese Pregnant Sudanese Women. Open Access Maced J Med Sci. 2017 Apr 29;5(3):285-289. doi: 10.3889/oamjms.2017.059. eCollection 2017 Jun 15.

2. AbioyeAI, ParkS, RippK, McDonald EA, Kurtis JD, Wu H, PondTor S, Sharma S, Ernerudh J, Baltazar P, Acosta LP, Olveda RM, Tallo V, Friedman JF. Anemia of Inflammation during Human Pregnancy Does Not Affect Newborn Iron Endowment.J Nutr. 2018 Mar 1;148(3):427-436

3. Abu Hashim H, Foda O, Gha ty E. Lactoferrin or ferrous salts for iron deficiency anemia in pregnancy: A meta-analysis of randomized trials. Eur J Obstet Gynecol Reprod Biol. 2017 Dec;219:45-52. doi: 10.1016/j.ejogrb.2017.10.003. Epub 2017 Oct 4.

4. Accinelli RA, Leon-Abarca JA. Solid fuel use is associated with anemia in children. Environ Res. 2017 Oct;158:431-435. doi: 10.1016/j.envres.2017.06.032. Epub 2017 Jul 6.

5. Anderson G, Frazer DM. Current understanding of iron homeostasis. Am J Clin Nutr. 2017; 106(Suppl 6):1559S-1566S.

6. Bahizire E, D'Alessandro U, Dramaix M, Dauby N, Bahizire F, Mubagwa K, Donnen P. Malaria and Iron Load at the First Antenatal Visit in the Rural South Kivu, Democratic Republic of the Congo: Is Iron Supplementation Safe or Could It Be Harmful? Am J Trop Med Hyg. 2018 Feb;98(2):520-523. doi: 10.4269/ajtmh.17-0585.

7. Bartolo-Marchena M, Pajuelo-Ramírez J, Obregón-Cahuaya C, Bonilla-Untiveros C, Racacha-Valladares E, Bravo-Rebatta F. Propuesta de factor de corrección a las mediciones de hemoglobina por pisos altitudinales en menores de 6 a 59 meses de edad, en el Perú. Anales de la Facultad de Medicina. 2017; 78 (3): 281-286.

8. Becerra C, Gonzales GF, Villena A, de la Cruz D, Florián A. Prevalence of anemia in pregnant women at the Regional Hospital from Pucallpa, Peru. Pan-American Journal Public Health 1998; 3: 285-292

9. Bencaiova G, Breymann C. Mild anemia and pregnancy outcome in a Swiss collective. JPregnang .2014;2014:307535. doi: 10.1155/2014/307535.

10. Beutler E, Waalen J. The definition of anemia: what is the lower limit of normal of the blood hemoglobin concentration?Blood. 2006 Mar 1;107(5):1747-50

11. Blanc B, Finch CA, Hallberg L, et al. Nutritional anaemias. Report of a WHO Scientific Group. WHO Tech Rep Ser. 1968;405:1-40

12. Breymann C, Milman N, MezzacasaA, Bernard R, Dudenhausen J; FER-ASAP investigators. Ferric carboxymaltose vs. oral iron in the treatment of pregnant women with iron deficiency anemia: an international, open-label, randomized controlled trial (FER-ASAP). J Perinat Med. 2017 May 24;45(4):443-453. doi: 10.1515/jpm-2016-0050.

13. Buzyan LO. Mild anemia as a protective factor against pregnancy loss. Int J Risk Saf Med. 2015;27 Suppl 1:S7-8. doi: 10.3233/JRS-150668.

14. Daru J, Allotey J, Peña-Rosas JP, Khan KS. Serum ferritin thresholds for the diagnosis of iron deficiency in pregnancy. A systematic review. Transf Med. 2017; 27(3):167-174.

15. Darwish AM, Fouly HA, Saied WH, Farah E. Lactoferrin plus health education versus total dose infusion (TDI) of lowmolecular weight (LMW) iron dextran for treating iron deficiency anemia (IDA) in pregnancy: a randomized o ntrolled trial. J Matern Fetal Neonatal Med. 2018 Jan 25:17. doi: 10.1080/14767058.2018.1429396. [Epub ahead of print]

16. De Benoist B, McLean E, Egli I, Cogswell M. Worldwide prevalence of anemia 1993-2005. WHO Global Datbase on Anemia. WHO Press: Switzerland. 2008: 1-40.

17. De Maeyer E, Adiels-Tegman M. The prevalence of anaemia in the world. World Health Statistics Quarterly, 1985:38::302316.

18. Dewey KG, Oaks BM. U-shaped curve for risk associated with maternal hemoglobin, iron status, or iron supplementation. Am J Clin Nutr. 2017; 106 (Suppl 6):1694S-1702S.

19. Domellöf M, Dewey KG, Lönnerdal B, Cohen RJ, Hernell O. The diagnostic criteria for iron deficiency in infants should be reevaluated. J Nutr. 2002 Dec;132(12):3680-6. 
20. Elmugabil A, Raiy s DA, Abdelmageed RE, Adam I, Gasim GI. High level of hemoglobin, white blood cells and obesity among Sudanese women in early pregnancy: a crossset ional study. Future Sci OA. 2017 Apr 4;3(2):FSO182. doi: 10.4155/fsoa-2016-0096. eCollection 2017 Jun.

21. Ganz T. Iron and infection. Int J Hematol. 2018 Jan;107(1):715. doi: 10.1007/s12185-017-2366-2. Epub 2017 Nov 16.

22. Ganz T, Jung G, Naeim A, Ginzburg Y, Pakbaz Z, Walter PB, Kautz L, Nemeth E. Immunoassay for human serum erythroferrone. Blood. 2017 Sep 7;130(10):1243-1246. doi: 10.1182/blood-2017-04-777987. Epub 2017 Jul 24.

23. Gonzales GF, Salirrosas A. Arterial on saturation in healthy newborns delivered at term in Cerro de Pasco (4340 m) and Lima (150 m). Reprod Biol Endocrinol. 2005 Sep $12 ; 3: 46$

24. Gonzales GF, Steenland K, Tapia V. Maternal hemoglobin level and fetal outcome at low and high altitudes. Am J Physiol Regul Integr Comp Physiol. 2009 Nov;297(5):R1477-85

25. Gonzales GF, Tapia V., Carrillo CE: Stillbirth rates in Peruvian populations at high altitude. International Journal of Gynecology \& Obstetrics. 2008; 100:221-227

26. Gonzales GF, Tapia V, Gaso M, Carrillo C. [Maternal hemoglobin in Peru: regional differences and its association with adverse perinatal outcomes]. [Article in Spanish]. Rev Peru Med Exp Salud Publica. 2011 Jul-Sep;28(3):484-91.

27. Gonzales GF, Tapia V, Gasco M. Correcting haemoglobin cut-offs to define anaemia in high-altitude pregnant women in Peru reduces adverse perinatal outcomes. Archives of Gynecology and Obstetrics. 2014 Jul;290(1):65-74. doi: 10.1007/s00404-014-3182-z. Epub 2014 Feb 27. (Factor de Impacto: 1.33)

28. Gonzales GF, Rubín de Celis V, Begazo J, Hinojosa MDR, Yucra S, Zevallos A, Tapia V. Correcting the cut-off point of hemoglobin at high altitude favors misclassification of anemia, erythrocytosis and excessive erythrocytosis. Am J Hematol. 2018 Jan;93(1):E12-E16. doi: 10.1002/ajh.24932.

29. Gonzales GF, Fano D, Vásquez-Velasquez C. Necesidades de investigación para el diagnóstico de anemia en poblaciones de altura. Rev Per Med Exp Salud Publica. 2017;34(4):1-10

30. Houston BL, Hurrie D, Graham J, Perija B, Rimmer $\mathrm{E}$, Rabbani R, Bernstein CN, Tur geon AF, Fergusson DA, Houston DS, Abou-Setta AM, Zaryshanski R. Efficacy of iron supplementation on fatigue and physical capacity in non-anaemic iron-deficient adults: a systematic review of randomised controlled trials. BMJ Open. 2018; 8(4):e019240. Doi. 10.1136/ bmjopen-2017-019240.

31. INEI. Perú. Encuesta Demográfica y de Salud Familiar. Lima:INEI 2017.

32. Karaskova E, Volejnikova J, Holub D, Velganova-Veghova M, Sulovska L, Mihal V, Horvathova M, Pospisilova D. Hepcidin in newly diagnosed inflammatory bowel disease in b ildren. J Paediatr Child Health. 2018 Jun 20. doi: 10.1111/ jpc.14093. [Epub ahead of print]

33. Khoigani MG, Goli S, Hasanzadeh A. The relationship of hemoglobin and hematocrit in the first and second half of pregnancy with pregnancy outcome. Iran J Nurs Midwifery Res. 2012 Feb;17(2 Suppl 1):S165-70.

34. Kozuki N, Lee AC, Katz J; Child Health Epidemiology Reference Group. Moderate to severe, but not mild, maternal anemia is associated with increased risk of smallfor-gestational-age outcomes. J Nutr. 2012 Feb;142(2):35862. doi: 10.3945/jn.111.149237

35. Krafft A. Iron supplementation in pregnancy. Author's reply to Steer. BMJ 2013; 347: f4868.
36. Langer AL, Ginzburg YZ. Role of hepcidin-ferroportin axis in the pathophysiology, diagnosis, and treatment of anemia of chronic inflammation. Hemodial Int. 2017 Jun;21 Suppl 1:S37-S46. doi: 10.1111/hdi.12543.

37. LittleMP,BrocardP,ElliottP,SteerPJ.Hemoglobinconcentration in pregnancy and perinatal mortality: a London-based cohort study. Am J Obstet Gynecol. 2005 Jul;193(1):220-6.

38. Low MS, Speedy J, Styles CE, De-Regil LM, Pasricha SR. Daily iron supplementation For improving anaemia, iron status and health in menstruating women. Cochrane Databse Syst Rev 2016; 4: CD009747. Doi: 10.1002/14651858

39. ML ean E, Cogswell M, Egli I, Wojdyla D, de Benoist B. Worldwide prevalence of anaemia, WHO Vitamin and Mineral Nutrition Information System, 1993-2005. Public Health Nutr. 2009 Apr;12(4):444-54. doi: 10.1017/ S1368980008002401. Epub 2008 May 23.

40. Milman N, Pedersen AN. Blood haemoglobin concentrations are higher in smokers and heavy alcohol consumers than in non-smokers and abstainers: should we adjust the reference range? Ann Hematol. 2009 Jul;88(7):687-94. doi: 10.1007/ s00277-008-0647-9.

41. Milman N. Iron in pregnancy: How do we secure an appropriate iron status in the mother and child? Ann Nutr Metab. 2011;59(1):50-4. doi: 10.1159/000332129. Epub 2011 Nov 25.

42. Milman N. Prepartum anaemia: prevention and treatment. Ann Hematol. 2008 Dec;87(12):949-59. doi: 10.1007/s00277008-0518-4.

43. Milman N, Bergholt ., Byg KE, Eriksen L, Hvas AM. Reference intervals for haematological variables during normal pregnancy and postpartum in 434 healthy Danish women. European Journal of Haematology. 2007;79: 39-46

44. Mirc ov CSG, Wilkins SJ, Hung GCC, Helman SL, Anderson GJ, Fraz $r$ DM. Circulating iron levels influence the regulation of hepcidin following stimulated erythropoiesis. Haematologica. 2018 Jun 14. pii: haematol.2017.187245. doi: 10.3324/haematol.2017.187245. [Epub ahead of print]

45. Muñoz M, Peña-Rosas JP, Robinson S, Milman N, Holzgreve W, Breymann C, Goffinet F, Nizard J, Christory F, Samama $\mathrm{CM}$, Hardy JF. Patient blood management in obstetrics: management of anaemia and haematinic deficiencies in pregnancy and in the post-partum period: NATA consensus statement. Transfus Med. 2018 Feb;28(1):22-39. doi: 10.1111/tme.12443.

46. Nair M, Churb ill D, Robinson S, Nelson-Piercy C, Stanworth SJ, Knight M. Association between maternal haemoglobin and stillbirth: a cohort study among a multi-ethnic population in England. Br J Haematol. 2017 Dec;179(5):829-837. doi: 10.1111/bjh.14961. Epub 2017 Oct 26.

47. Nairz M, Dib tI S, Sb roll A, Haschka D, Tymoszuk P, Theurl I, Weiss G. Iron and innate antimicrobial immunity-Depriving the pathogen, defending the host. J Trace Elem Med Biol. 2018 Jul;48:118-133. doi: 10.1016/j.jtemb.2018.03.007. Epub 2018 Mar 10.

48. Nemeth E, Ganz T. Anemia of inflammation. Hematol Oncol Clin North Am. 2014 Aug;28(4):671-81, vi. doi: 10.1016/j. hoc.2014.04.005. Epub 2014 May 28.

49. Papp F, Ráz G, Lénárt I, Kóbor J, Bereczki C, Karg $\mathrm{E}$, Baráth Á. [Maternal and neonatal vitamin $\mathrm{B}_{12}$ deficiency detected by expanded newborn screening]. [Article in Hungarian]. Orv Hetil. 2017 Dec;158(48):1909-1918. doi: 10.1556/650.2017.30901.

50. Peña-Rosas JP, De Regil LM, Qoeswell T, Viteri FE. Daily oral iron supplementation during pregnancy. Cochrane Database Syst Rev. 2012; 12: CD004736

51. Peña-Rosas JP, De-Regil LM, Garcia-Casal MN, Dowswell T. Daily oral iron supplementation during pregnancy. Cob rane 
Database Spt Rev. 2015 Jul 22;(7):CD004736. doi: 10.1002/14651858.CD004736.pub5.

52. Räisänen S, Kancherla V, Gissler M, Kramer MR, Heinonen $\mathrm{S}$. Adverse perinatal outcomes associated with moderate or severe maternal anaemia based on parity in Finland during 2006-10. Paediatr Perinat Epidemiol. 2014 Sep;28(5):372-80.

53. Rosa L, Cutone A, Lepanto MS, Paesano R, Valenti P. Lactoferrin: A Natural Glycoprotein Involved in Iron and Inflammatory Homeostasis. Int J Mol Sci. 2017 Sep 15;18(9). pii: E1985. doi: 10.3390/ijms18091985.

54. Sanghavi M, Rutherford JD. Cardiovascular physiology of pregnancy. Cira lation. 2014 Sep 16;130(12):1003-8.

55. Sangkhae V, Nemeth E. Regulation of the Iron Homeostatic Hormone Hepcidin. Adv Nutr. 2017 Jan 17;8(1):126-136. doi: 10.3945/an.116.013961.

56. Sharma P, Puri N. A new role for mast cells as scavengers for clearance of erythrocytes damaged due to oxidative stress. Immunol Lett. 2018 Jul;199:23-35. doi: 10.1016/j. imlet.2018.04.002. Epub 2018 Apr 7.

57. Smith AD, Warren MJ, Refsum H. Vitamin B. Adv Food Nutr Res. 2018;83:215-279. doi: 10.1016/bs.afnr.2017.11.005.

58. Steer PJ. Maternal hemoglobin 0 ne ntration and birth weight. Am J Clin Nutr. 2000 May;71(5 Suppl):1285S-7S.

59. Steer PJ.Healthy pregnant women still don't need routine iron supplementation. BMJ 2013; 347: f4866.

60. Stevens GA, Finucane MM, De-Regil LM, Paciorek CJ, Flaxman SR, Branca F, Peña-Rosas JP, Bhutta ZA, Ezzati M; Nutrition Impact Model Study Group (Anaemia). Global, regional, and national trends in haemoglobin concentration and prevalence of total and severe anaemia in children and pregnant and non-pregnant women for 1995-2011: a systematic analysis of population-representative data. Lane t Glob Health. 2013 Jul;1(1):e16-25.
61. Thurnham DI, McCabe LD, Haldar S, Wieringa FT, Northrop-Clewes CA, McCabe GP. Adjusting plasma ferritin concentrations to remove the effects of subclinical inflammation in the assessment of iron deficiency: a metaanalgi s.Am J Clin Nutr. 2010 Sep;92(3):546-55. doi: 10.3945/ ajcn.2010.29284

62. Uijterschout L, Domellof M, Berglund SK, Abbink M, Vos P, Rovekamp L, Boersma B, Lagerqvist C, Hudig C, van Goudoever JB, Brus F. Serum hepcidin in infants born after 32 to 37 wk of gestational age. Pediatr Res 2016; 79(4):608-13.

63. Vallet N; Club du Globule Rouge et du Fer. [The role of erythroferrone in iron metabolism: From experimental results to pathogenesis]. [Article in French]. Rev Med Interne. 2018 Mar;39(3):178-184. doi: 10.1016/j.revmed.2017.05.008. Epub 2017 Jun 27.

64. WHO. The prevalence of anemia in women: A tabulation of available Information. 1992 (WHO/MCH/MSM/92.2)

65. WHO. Haemoglobin Concentrations for the Diagnosis of Anaemia and Assessment of Severity. Vitamin and Mineral Nutrition Information System.World Health Organization, Geneva, Switzerland.2011.

66. Zaric BL, Obradovic M, Bajic V, Haidara MA, Jovanovic $M$, Isenovic ER. Homocysteine and Hyperhomocysteinaemia. Curr Med Chem. 2018 Mar 12. doi: 10.2174/0929867325666 180313105949.

\section{Correspondencia:}

Autor:Gustavo Francisco Gonzales Rengifo

E-mail: gustavo.gonzales@upch.pe

Teléfono: (01)319-0000 (Anexo: 233213)

Dirección: Avenida Honorio Delgado 430 Urb. Ingeniería San Martin de Porres, Lima, Perú 